\title{
Absorption of Bile Pigments by the Gall Bladder*
}

\author{
J. Donald Ostrow $\ddagger$ \\ (From the Gastrointestinal Units, Department of Medicine, Western Reserve University \\ School of Medicine, and University Hospitals, Cleveland, Ohio)
}

\begin{abstract}
A technique is described for preparation in the guinea pig of an in situ, isolated, vascularized gall bladder that exhibits normal absorptive functions. Absorption of labeled bile pigments from the gall bladder was determined by the subsequent excretion of radioactivity in hepatic bile.

Over a wide range of concentrations, unconjugated bilirubin $-{ }^{14} \mathrm{C}$ was well absorbed, whereas transfer of conjugated bilirubin proceeded slowly. Mesobilirubinogen ${ }^{8} \mathrm{H}$ was absorbed poorly from whole bile, but was absorbed as rapidly as unconjugated bilirubin from a solution of pure conjugated bile salt.

Bilirubin absorption was not impaired by iodoacetamide, $1.5 \mathrm{~mm}$, or dinitrophenol, $1.0 \mathrm{~mm}$, even though water transport was affected. This indicated that absorption of bilirubin was not dependent upon water transport, nor upon energy-dependent processes. The linear relationship between absorption and concentration of pigment at low concentrations in bile salt solutions suggested that pigment was transferred by passive diffusion. At higher pigment concentrations or in whole bile, this simple relationship was modified by interactions of pigment with bile salts and other constituents of bile. These interactions did not necessarily involve binding of bilirubin in micelles.

The slow absorption of the more polar conjugates and photo-oxidative derivatives of bilirubin suggested that bilirubin was absorbed principally by nonionic, and partially, by ionic diffusion.

Concentrations of pure conjugated bile salts above $3.5 \mathrm{~mm}$ were found to be injurious to the gall bladder mucosa. This mucosal injury did not affect the kinetics of bilirubin absorption.

During in vitro incubation of bile at $37^{\circ} \mathrm{C}$, decay of bilirubin and hydrolysis of the conjugate proceeded as first-order reactions. The effects of these processes on the kinetics of bilirubin absorption, and their possible role in the formation of "white bile" and in the demonstrated appearance of unconjugated bilirubin in hepatic bile, are discussed.
\end{abstract}

\section{Introduction}

Reviews of the absorptive functions of the gall bladder $(2,3)$ have stressed the transport of water

* Received for publication 23 September 1966 and in revised form 6 July 1967.

Presented in part at the Gastrointestinal Section of the 22nd Annual Meeting of the American Federation for Clinical Research 2 May 1965, at Atlantic City, N. J. (1).

This work was supported by Research Grant AM06840 from the National Institutes of Health, U. S. Public Health Service.

¥ Address requests for reprints to Dr. J. Donald Ostrow, Department of Medicine, University Hospitals, 2065 Adelbert Road, Cleveland, Ohio 44106. and electrolytes, and have reiterated the prevailing belief that the organic constituents of bile are not absorbed. This belief evolved from experiments with dogs $(4,5)$, in which absorption of these organic compounds was determined from their net disappearance from the gall bladder, assayed colorimetrically. Since these techniques were limited in sensitivity and accuracy, some absorption of these compounds may have occurred and yet not have been detected. Therefore, it seemed desirable to utilize sensitive isotopic methods to reexamine the supposed impermeability of the gall bladder to the major organic constituents of bile. 
The present paper describes the absorption of labeled bile pigments from the isolated, in situ gall bladder of the guinea pig; a companion paper $^{1}$ reports similar experiments with bile salts, sulfobromophthalein, and iodipamide. In both investigations, absorption of the labeled compounds from the gall bladder is determined from the subsequent excretion of radioactivity in hepatic bile. This method is shown to be valid and highly reproducible when applied to substances that are rapidly excreted by the liver. Contrary to published studies performed with unlabeled bile pigments (4), the results indicate that the gall bladder does absorb appreciable quantities of bilirubin, principally in the nonconjugated form. Similar absorption of radioactive mesobilirubinogen is also demonstrated. It is shown further that the transport of bile pigments by the gall bladder mucosa is probably not an active, energy-dependent process. Other data are presented concerning the decay of total bilirubin and the hydrolysis of conjugated bilirubin in mammalian bile. The significance of these data is discussed in relation to the formation of "white bile" and to the current belief that bilirubin must be conjugated in order to be secreted into the bile.

\section{Methods}

Labeled bile pigments. Crystalline bilirubin- ${ }^{14} \mathrm{C}$ (462$1250 \mathrm{dpm} / \mu \mathrm{g}$ ) was prepared biosynthetically from glycine- $2{ }^{14} \mathrm{C}^{2}(6)$. Crystalline mesobilirubinogen $-{ }^{8} \mathrm{H}^{3}(13.6$ $\times 10^{3} \mathrm{dpm} / \mu \mathrm{g}$ ) was prepared by sodium-amalgam reduction of crystalline bilirubin in the presence of ${ }^{3} \mathrm{H}_{2} \mathrm{O}(7)$.

Bile. Hepatic bile was collected from guinea pigs and Sprague-Dawley rats under pentobarbital anesthesia during the first $6 \mathrm{hr}$ after catheterization of the common duct. Canine bile was obtained by needle puncture of the gall bladder under pentobarbital anesthesia. Uninfected human bile was obtained from T-tube drainage of the common duct of patients with normal liver functions who had undergone cholecystectomy 5-7 days previously. All biles were collected on ice and in the dark.

Bile Salt Solutions. Sodium taurocholate 4 (Lot. 46040 ) or sodium taurochenodeoxycholate 4 (Lot. 53264) was dissolved in $0.85 \%$ saline. Deoxycholic acid ${ }^{4}$ (Lot. 53440) was dissolved in $0.85 \%$ saline containing an

1 Ostrow, J. D., D. K. Bloomfield, and R. P. Levy. Absorption by the gall bladder of bile salts, sulfobromophthalein, and iodipamide. In preparation.

2 New England Nuclear Corporation, Boston, Mass.

${ }^{3}$ Graciously provided by Dr. Roger Lester.

4 Grade A, California Biochemicals Corporation, Los Angeles, Calif. equimolar quantity of sodium hydroxide. Purity of these bile salts, both before and after alkaline hydrolysis of the conjugates, was determined by thin-layer chromatography on silica gel $\mathrm{G}$, elution into $65 \%$ sulfuric acid, and spectrophotometric quantitation at $320 \mathrm{~m} \mu$ (8). The two conjugated bile salts contained less than $2.5 \%$ of the corresponding free bile acid and less than $8.0 \%$ unmeasured, nonbile acid impurities. The deoxycholic acid contained $21 \%$ chenodeoxycholic acid.

\section{Solutions for instillation into the gall bladder}

Unconjugated bilirubin- ${ }^{14} \mathrm{C}$ or mesobilirubinogen- ${ }^{3} \mathrm{H}$. $150-900 \mu \mathrm{g}$ of the crystalline labeled pigment was dissolved quickly in $0.4 \mathrm{ml}$ of $0.1 \mathrm{~N}$ sodium hydroxide, and $0.6 \mathrm{ml}$ of isotonic, calcium-free, Krebs-Ringer phosphate (KRP) buffer, $\mathrm{pH} \mathrm{7.4,} \mathrm{(9)} \mathrm{was} \mathrm{added.} \mathrm{To} \mathrm{this} \mathrm{was}$ added $3.2 \mathrm{ml}$ of guinea pig bile, rat bile, or bile salt solution. In three experiments, equimolar quantities of unlabeled unconjugated bilirubin and mesobilirubinogen ${ }^{3} \mathrm{H}$ were dissolved in $3.5 \mathrm{~mm}$ taurocholate solution.

Effects of Inhibitors. In some experiments, crystalline bovine albumin, ${ }^{5}$ iodoacetamide, ${ }^{6}$ or dinitrophenol 7 was dissolved in the guinea pig bile before mixing with the buffered alkaline solution of labeled unconjugated bilirubin.

Conjugated bilirubin- ${ }^{14}$ C. $\quad 200-1000 \mu \mathrm{g}$ of crystalline bilirubin $-{ }^{14} \mathrm{C}$ in a neutral buffered solution of $2.0 \mathrm{~g} / 100 \mathrm{ml}$ of bovine albumin was administered intravenously to a guinea pig or rat with an external bile fistula. The excreted bile was collected on ice over the next 1-4 hr. To $3.2 \mathrm{ml}$ of this bile, containing conjugated bilirubin $-{ }^{14} \mathrm{C}$, was added $0.6 \mathrm{ml}$ of $\mathrm{KRP}$ buffer and $0.4 \mathrm{ml}$ of $0.1 \mathrm{~N}$ sodium hydroxide.

Photo-oxidized bilirubin- ${ }^{14} \mathrm{C}$. Labeled bilirubin, 170 $250 \mu \mathrm{g}$, dissolved in $0.4 \mathrm{ml}$ of $0.1 \mathrm{~N}$ sodium hydroxide was exposed for 1,3 , or $5 \mathrm{hr}$ to a 100 watt, unfiltered, mercury spot lamp ${ }^{8}$ at a distance of $18 \mathrm{~cm}$. The alkaline solutions become diazo-negative after $1 \mathrm{hr}$ and colorless after $5 \mathrm{hr}$ of exposure as progressively more polar, watersoluble derivatives of bilirubin- ${ }^{14} \mathrm{C}$ were formed (10). To these solutions of labeled bilirubin derivatives, 0.6 $\mathrm{ml}$ of KRP buffer and $3.2 \mathrm{ml}$ of guinea pig bile were added.

Immediately after mixing, all pigment solutions were adjusted to $\mathrm{pH} 8.2$ with $1.0 \mathrm{~N}$ hydrochloric acid, and centrifuged in the cold for $5 \mathrm{~min}$ at $900 \mathrm{~g}$. The clear supernatant fluids were kept in the dark on ice and, before instillation into the gall bladder, aliquots were taken for assay of pigment content and radioactivity.

Operative procedure, (Fig. 1), was adapted from the technique of Herman, Wilson, and Kazyak (11). Albino, female guinea pigs ${ }^{9}$ weighing $350-450 \mathrm{~g}$ were fasted: for $18 \mathrm{hr}$ but allowed water ad lib. Anesthesia was in-

5 Armour Pharmaceutical Company, Kankakee, Ill.

${ }^{6}$ Nutritional Biochemicals Corporation, Cleveland, Qbio.

7 Matheson Scientific Company, Cleveland, Ohio.

8 PAR 38 Spot, Catalog number H-100-PSP44-4, General Electric Company, Nela Park, Cleveland, Ohio.

๑ Sterett or Herrick Companys, Cleveland, Ohio. 


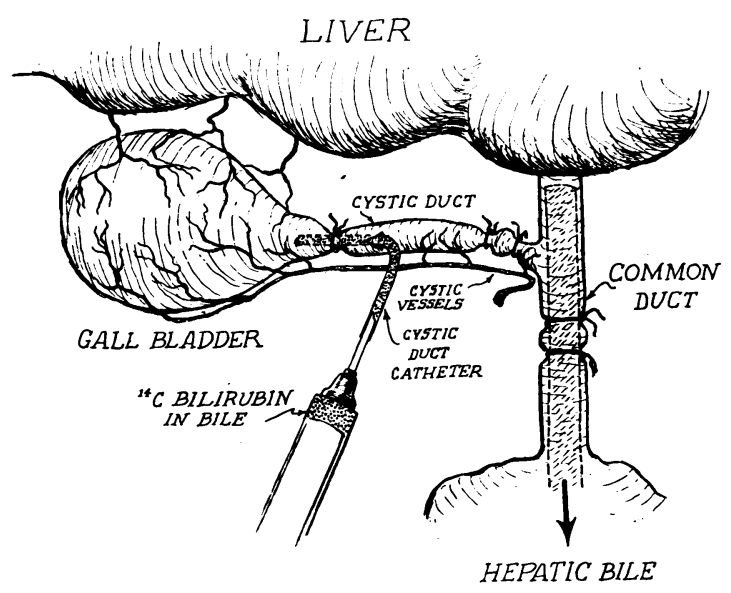

Fig. 1. Operative PROCEdURE For instillation of SOLUTIONS OF LABELED PIGMENT INTO ISOLATED, VASCULARIZED GALL BLADDER. For details, see text.

duced with pentobarbital in isotonic saline, $3 \mathrm{mg}(0.1$ $\mathrm{ml}) / 100 \mathrm{~g}$ of body weight, administered intraperitoneally. 30 min later, anesthesia was completed with small amounts of ether, the abdomen opened in the midline, and the xiphoid amputated. The cystic duct was freed of its mesenteric atta:hments and the cystic vessels dissected from the duct wall. Size 4-0 silk ligatures were then passed around each end of the cystic duct and the distal ligature tied, thus isolating the gall bladder with its circulation intact. The common duct was then cannulated with a PE-50 polyethylene catheter ${ }^{10}$ that was exteriorized through the right flank to permit continuous collection of hepatic bile. Through an incision in the cystic duct, a PE-10 polyethylene catheter ${ }^{10}$ was introduced just into the ampulla through which the gall bladder was emptied and irrigated gently with isotonic saline until the returns were colorless. $1.0 \mathrm{ml}$ of the appropriate solution of labeled bile pigment was then instilled into the emptied gall bladder, and the catheter withdrawn as the proximal ligature on the cystic duct was tied tightly. The abdomen was closed and the animal allowed to awaken in a restraining cage. Hydration was maintained by hourly replacement of the biliary losses with an equal volume of $2.5 \%$ glucose- $0.45 \%$ saline, administered subcutaneously.

Collection and analysis of fluids and tissues. During the $6 \mathrm{hr}$ after instillation of the pigment solution into the gall bladder, all hepatic bile and urine were collected on ice and assayed for total radioactivity. The animal was then reexplored under ether anesthesia and, by cardiopuncture, exsanguinated into a tube containing EDTA ${ }^{11}$ as an anticoagulant. The gall bladder was removed from the liver bed and suspended from a hemostat applied to the severed cystic duct. A No. 24 hypodermic needle attached to a $1.0 \mathrm{ml}$ tuberculin syringe was introduced

10 Clay-Adams Company, New York, N. Y.

11 Vacutainer, Becton-Dickinson Company, Rutherford, N. J. through the ampulla, and the gall bladder was emptied and rinsed four times with $0.4 \mathrm{ml}$ of bovine albumin $(1 \mathrm{mg}$ / $\mathrm{ml}$ ) in KRP buffer. The pooled aspirates were diluted to $2.0 \mathrm{ml}$ and the content of pigment and radioactivity determined.

The liver was removed, rinsed with saline, blotted and weighed, and samples totaling 1.0-1.5 g taken from each major lobe. These were homogenized three times with $3.0 \mathrm{ml}$ of chloroform-methanol $(1: 1, \mathrm{v} / \mathrm{v})$, using a manually-driven, TenBroeck glass homogenizer. ${ }^{12}$ The pooled extracts were diluted to $10.0 \mathrm{ml}$. The irrigated gall bladder wall was similarly homogenized with half as much solvent. Recovery of radioactivity added to six samples of liver as bilirubin ${ }^{14} \mathrm{C}$ averaged $68 \pm 4 \%$ ( \pm SD).

Chemical determinations. Total and direct-reacting bilirubin concentrations of the instilled and residual gall bladder solutions were determined spectrophotometrically by a micromodification of the diazo method of Malloy and Evelyn (12), with the direct reaction read at 15 min. Direct-reacting bilirubin was taken to represent conjugated bilirubin although the two are not exactly equal $(13,14)$. Total bilirubin in excreted fistula bile was determined by the diazo method of Michaëlsson (15). Urobilinogen was assayed spectrophotometrically by a micromodification of the Ehrlich aldehyde method of Watscn and Hawkinson (16).

Radioassay techniques. Aliquots of hepatic bile (0.5 $\mathrm{ml})$, instilled pigment solutions $(0.05 \mathrm{ml})$, residual gall bladder contents $(0.2 \mathrm{ml})$, urine $(1.0 \mathrm{ml})$, and plasma $(0.5 \mathrm{ml})$ were pipetted into $20-\mathrm{ml}$ low-potassium glass counting vials, ${ }^{13}$ frozen in dry-ice acetone, and lyophilized in a vacuum desiccator over concentrated sulfuric acid (17). The dried powders were dissolved in $2.0 \mathrm{ml}$ of $0.5 \mathrm{M}$ Hyamine-methanol, 13 at $70^{\circ} \mathrm{C}$. $1 \mathrm{ml}$ of the chloroform-methanol extracts of homogenized liver or gall bladder wall was mixed directly with $1.0 \mathrm{ml}$ of $1.0 \mathrm{M}$ Hyamine-methanol. All samples were then blended with $15.0 \mathrm{ml}$ of scintillator solution, ${ }^{14}$ and $0.1 \mathrm{ml}$ of glacial acetic acid was added. Counting was performed in a liquid scintillation spectrometer 15 to a total of 10,000 counts or $40 \mathrm{~min}$. For each ${ }^{14} \mathrm{C}$ sample, total dpm was calculated utilizing counting efficiences obtained from channel-ratios initially determined on selected samples with toluene $-{ }^{14} \mathrm{C}^{2}$ as internal standard. Efficiencies ranged from 42 to $65 \%$. Efficiency of each ${ }^{3} \mathrm{H}$ sample was determined with toluene- ${ }^{8} \mathrm{H}^{2}$ as internal standard, and each ranged from 3.2 to $8.5 \%$

Calculation of the quantity of pigment absorbed. Absorption of labeled pigment was determined from the

12 Scientific Glass Apparatus Company, Bloomfield, N. J.

13 Packard Instrument Company, La Grange, Ill.

14 2,5-Diphenyloxazole, $4 \mathrm{~g} / \mathrm{liter}$, and $50 \mathrm{mg} / \mathrm{liter} 1,4-$ bis[2-(5-phenyloxazolyl)]benzene, dissolved in dry toluene. Prepared from Liquifluor, Pilot Chemical Company, Watertown, Mass.

${ }^{15}$ Model 720-B, Nuclear Chicago Corporation, Chicago, III. 
radioactivity excreted in hepatic bile according to Equation 1.

$\mu$ moles pignent absorbed $=\mu$ moles pigment initially from gall bladder $=$ instilled into gall bladder

$$
\times \frac{\mathrm{dpm} \text { excreted in hepatic bile }}{\mathrm{dpm} \text { instilled into gall bladder }}
$$

Criteria of a satisfactory experiment. To be considered acceptable, an experiment had to meet the following standards: (a) the animal suffered no cardiac or respiratory distress and was active within $90 \mathrm{~min}$ after completion of the operation; $(b)$ isolation, cannulation, and rinsing of the gall bladder were accomplished without undue distention of, or traction on, the viscus; $(c)$ the $6 \mathrm{hr}$ bile flow was greater than $3.0 \mathrm{ml} / 100 \mathrm{~g}$ of body weight; $(d)$ maximum rates of bile flow and isotope excretion occurred during the first $60 \mathrm{~min}$ after instillation of labeled pigment into the gall bladder; $(e)$ the $6 \mathrm{hr}$ urine output exceeded $1.0 \mathrm{ml} / 100 \mathrm{~g}$ of body weight; $(f)$ at reexploration, blood flow in the cystic vessels was intact and the residual fluid in the gall bladder was clear and bloodless; $(g)$ after $6 \mathrm{hr}$, the volume of fluid in the gall bladder was $0.3-0.5 \mathrm{ml}$ if bile had been instilled or $0.1-0.2$ $\mathrm{ml}$ if bile salt solution had been instilled; and $(h)$ at least $95 \%$ of the instilled radioactivity was recovered at the end of the experiment.

\section{Ancillary studies}

Decay of bilirubin and urobilinogen in bile. $5.0 \mathrm{ml}$ of bile in a $10 \mathrm{ml}$ Erlenmeyer flask was incubated in the dark at $37^{\circ} \mathrm{C}$ under an air atmosphere, using a Dubnoff shaking incubator at $100 \mathrm{cycle} / \mathrm{min}$. At intervals, $0.5 \mathrm{ml}$ samples were removed, chilled on ice to arrest decay, and assayed for direct and total bilirubin and for urobilinogen by the methods previously described. Before assay, dilutions were made with distilled water where necessary. Cultures of the bile at the completion of incubation were uniformly sterile.

Excretion of labeled bile pigments by guinea pigs. A1bino, female guinea pigs ( $360 \mathrm{~g})$ were provided with an external common duct catheter after ligation of the cystic duct, and labeled pigment was injected into the femoral vein. The administered pigments were: (a) 0.34 $\mu$ mole of bilirubin- ${ }^{14} \mathrm{C}$ or mesobilirubinogen $-{ }^{8} \mathrm{H}$ dissolved in buffered guinea pig serum, or $(b)$ photo-oxidative derivatives, prepared as previously mentioned from 0.09 $\mu$ mole of bilirubin $-{ }^{14} \mathrm{C}$, and then neutralized with $2 \%$ buffered bovine albumin solution. These doses were equal to the largest quantity of each pigment that was instilled into the gall bladder during the studies of absorption. After injection, bile was collected in $5-30-\mathrm{min}$ periods for $6 \mathrm{hr}$, and each fraction was assayed for content of radioactivity and pigment by the methods described.

Excreted ${ }^{14} \mathrm{C}$ radioactivity in bilirubin. Bilirubin was crystallized (6) from hepatic bile pooled from six to nine animals, its specific activity was determined, and the per cent of total bile radioactivity in bilirubin calculated (18).

Excreted ${ }^{s} H$ radioactivity in urobilinogen was determined as described by Lester and Schmid for urobilinogen-



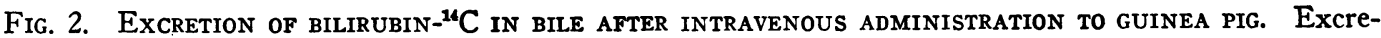
tion rate $(\mathrm{O}-\mathrm{O})$ and cumulative excretion (---O) of isotope in bile following intravenous injection of $0.34 \mu$ mole of bilirubin $-{ }^{14} \mathrm{C}$ dissolved in guinea pig serum. Each point represents the mean value from three animals, plotted as per cent of total injected radioactivity. 
${ }^{14} \mathrm{C}$ (19), and again pooled bile was used from six to nine animals.

Bilirubin-binding capacity of bovine albumin was determined by dialysis (20).

\section{Results}

Excretion of labeled pigments after intravenous administration. After intravenous injection of $0.34 \mu$ mole of albumin-bound, unconjugated bilirubin- ${ }^{14} \mathrm{C}$ to each of three guinea pigs (Fig. 2), excretion of isotope began within $5 \mathrm{~min}$ and attained the highest rates within $10 \mathrm{~min}$, declining exponentially thereafter. A mean of $64 \%$ of the injected radioactivity appeared in the bile in $30 \mathrm{~min}$ and $83 \%$ in $1 \mathrm{hr}$. In each animal, over $90 \%$ of the excreted label was identified as bilirubin- ${ }^{14} \mathrm{C}$. Excretion rates of mesobilirubinogen- ${ }^{8} \mathrm{H}$ were similar, with $58 \%$ of the label appearing in the bile in 30 min and $79 \%$ in $1 \mathrm{hr}$. Since hepatic clearance of pigment was extremely rapid, absorption of labeled pigments from the gall bladder could be determined from the subsequent biliary excretion of radioactivity.

Absorption of bilirubin-14C from guinea pig bile. Labeled bilirubin dissolved in $1.0 \mathrm{ml}$ of guinea pig bile, was instilled into the gall bladder, and hepatic bile was collected for $20 \mathrm{hr}$ thereafter. Four animals received $0.06-0.07 \mu \mathrm{mole} / \mathrm{ml}(3.5-4.2 \mathrm{mg} /$ $100 \mathrm{ml}$ ) of unconjugated bilirubin $-{ }^{14} \mathrm{C}$, whereas four others received the same concentration ${ }^{16}$ of labeled conjugate. As shown in Fig. 3, unconjugated bilirubin $-{ }^{14} \mathrm{C}$ was absorbed rapidly from the gall bladder and $15.5 \pm 1.1 \%$ (mean $\pm \mathrm{SE}$ ) of the instilled radioactivity appeared in the hepatic bile during the 1st hr. By contrast, after administration of conjugated bilirubin $-{ }^{14} \mathrm{C}$, absorption was significantly less rapid, with only $3.2 \pm 2.8 \%$

16 The concentration of pigment instilled refers only to the form of bilirubin (conjugated or unconjugated) that bears the label. The small amount of the unlabeled moiety (less than $0.015 \mu \mathrm{mole} / \mathrm{ml}$ ) present in the bile vehicle is disregarded.

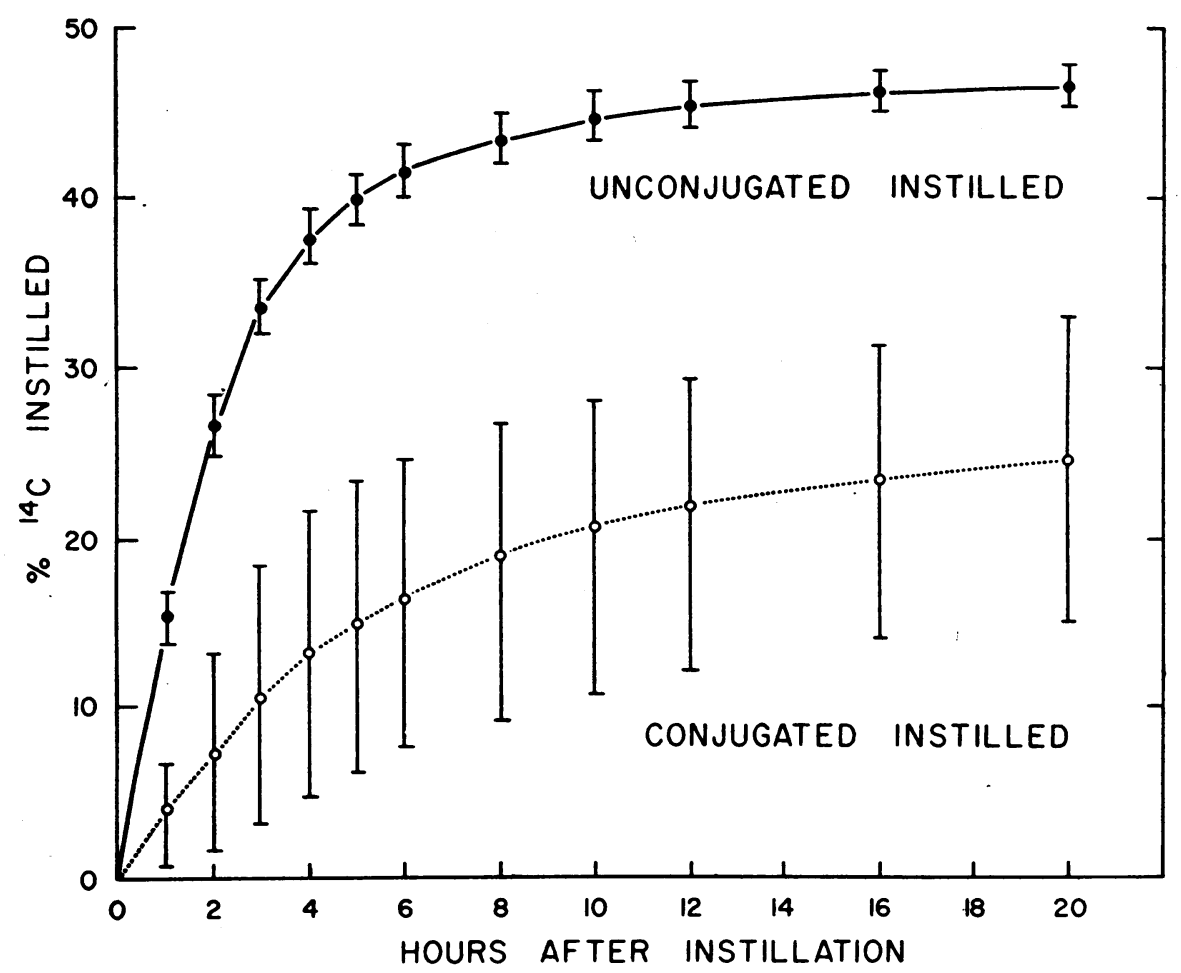

Fig. 3. Cumulative excretion of Radioactivity in hepatic bile after instillation INTO GALL BLADDER OF BILIRUBIN $-{ }^{14} \mathrm{C}$ DISSOLVED IN GUINEA PIG BILE. Each point represents the mean excretion $\pm \mathrm{SE}$, obtained with four animals, expressed as per cent of instilled radioactivity. Each animal received $0.06-0.07 \mu$ mole of labeled conjugated $\left(\mathrm{O}_{-}-\mathrm{O}\right.$ ) or unconjugated (O-O) bilirubin. 


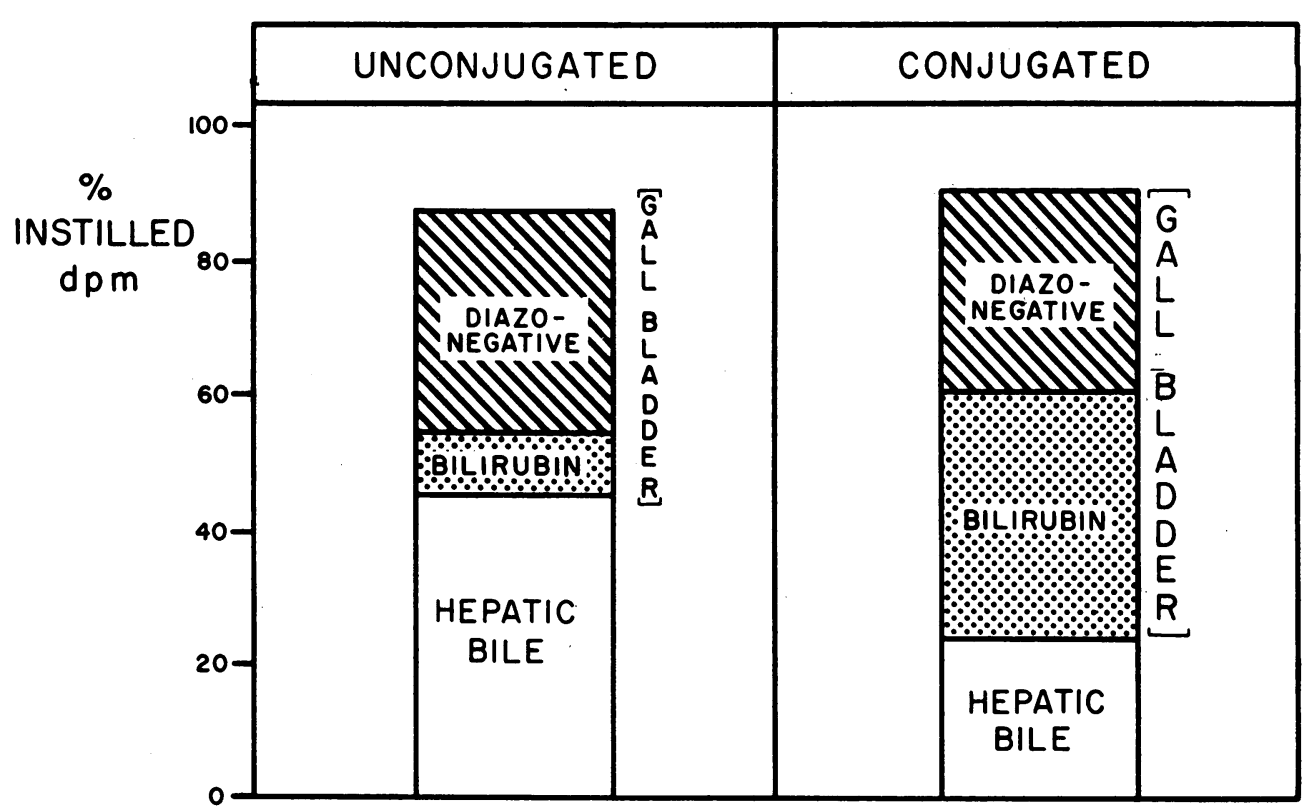

Fig. 4. Recovery OF RAdioACTIVITY AFTER INSTILLATION INTO GALl BLADDER OF UNCONJUGATED (LEFT) OR CONJUGATED (RIGHT) BILIRUBIN ${ }^{14} \mathrm{C}$ DISSOLVED IN GUINEA PIG BILE. Data are from the same experiments shown in Fig. 3. On each bar graph, the clear portion represents the per cent of ${ }^{14} \mathrm{C}$ excreted in hepatic bile, and the shaded portions the per cent of ${ }^{14} \mathrm{C}$ that remained in the gall bladder after $20 \mathrm{hr}$. This residual label in the gall bladder was identified in part as bilirubin $-{ }^{14} \mathrm{C}$ (dotted area) and in part as labeled diazo-negative derivatives of bilirubin (crosshatched area).

of the radioactivity excreted in $1 \mathrm{hr}(P<0.01) .{ }^{17}$ Rates of absorption of unconjugated pigment were highly reproducible among animals, whereas there was considerable variation after instillation of labeled conjugate. In both groups, after a rapid initial phase, absorption rates progressively declined, and, with unconjugated bilirubin $-{ }^{14} \mathrm{C}$, little radioactivity was excreted after the first $6 \mathrm{hr}$. Consequently, all subsequent experiments were terminated after a $6 \mathrm{hr}$ collection period.

After $20 \mathrm{hr}$, the gall bladder contained less than $0.2 \mathrm{ml}$ of the $1.0 \mathrm{ml}$ solution initially instilled. A mean of $90 \%$ of the instilled radioactivity was recovered in this residual fluid, plus the hepatic bile (Fig. 4). Total recovery from all tissues assayed consistently exceeded $95 \%$, including $0.4-1.1 \%$ in urine, $1.0-2.2 \%$ in the gall bladder wall, $1.7-3.9 \%$ in the liver, and $0.1-0.5 \%$ in the plasma. With both types of administered bilirubin, 76-123\% (mean of 7 pools $=106 \%$ ) of the radioactivity excreted in hepatic bile was identified by crystallization as bilirubin- ${ }^{14} \mathrm{C}$.

${ }^{17}$ Calculated by Student's $t$ test with Yates's correction for small sample size (21).
Analysis of the residual gall bladder contents after administration of unconjugated bilirubin- ${ }^{14} \mathrm{C}$ revealed that almost all the remaining label was present as diazo-negative, derivatives of bilirubin (Fig. 4). With conjugated bilirubin $-{ }^{14} \mathrm{C}$, the majority of residual radioactivity was still in the form of bilirubin, most of which was of the directreacting type.

Decay of bilirubin in bile. The above results suggested that considerable decay of bilirubin and hydrolysis of conjugate had occurred in the lumen of the gall bladder. To assess the rates of these processes, samples of bile were incubated in vitro in the dark under an air atmosphere. At $0^{\circ} \mathrm{C}$, there was no measurable decrease of either total or direct-reacting bilirubin over a period of $6 \mathrm{hr}$. During incubation of rat or guinea pig bile at $37^{\circ} \mathrm{C}$, direct and total bilirubin concentrations both decreased exponentially, with the former declining more rapidly, as illustrated in Fig. 5. The slope ${ }^{18}$ of the curve for total bilirubin was assumed to represent the rate of pigment decay, and the difference between the slopes of the curves for direct-

${ }^{18}$ Calculated by the method of least squares (21). 

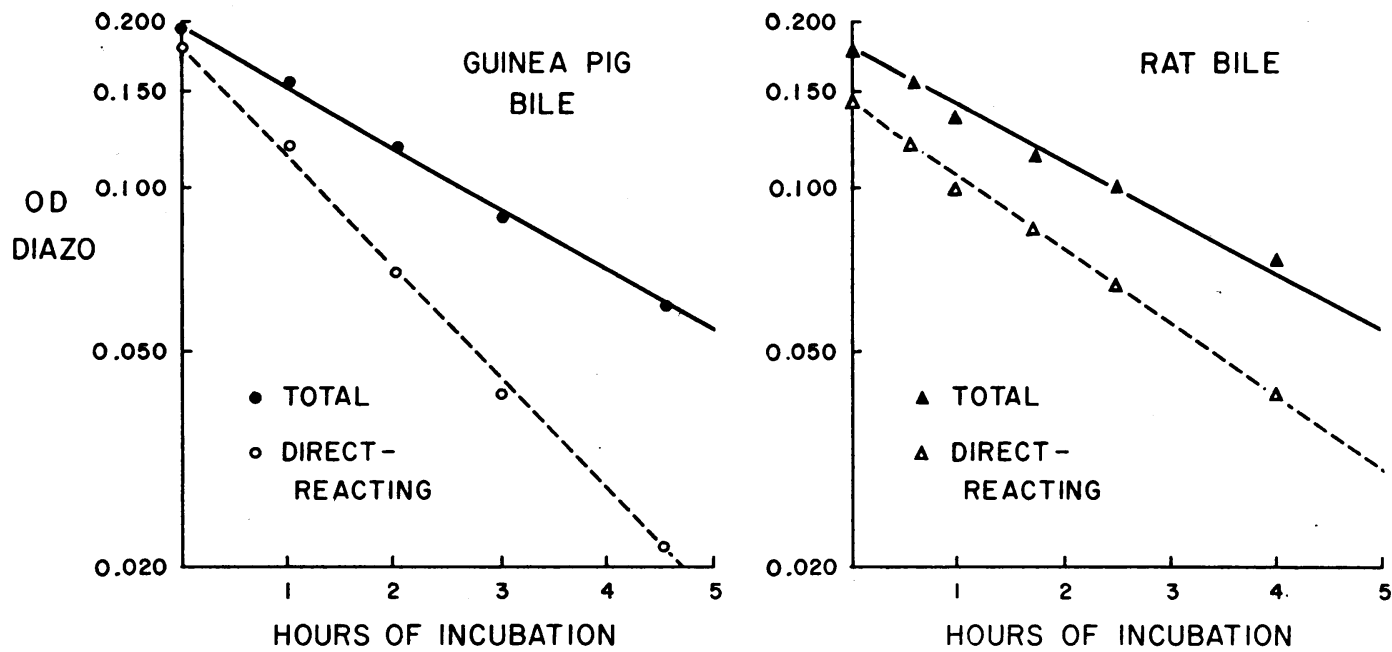

Fig. 5. DECAY OF BILIRUBin AND HYdRolysis of CONJUgate in a SAMPLE OF GUINEA PIg (LEFT) AND RAT BILE (RIGHT) AT $37^{\circ} \mathrm{C}$. Direct-reacting and total bilirubin concentrations expressed as intensity of MalloyEvelyn diazo reaction are plotted semilogarithmically against duration of incubation. Regression lines were calculated by the method of least squares (21), and rates of decay and hydrolysis determined as described in the text.

reacting and total bilirubin was assumed to represent the rate of hydrolysis of conjugated pigment (22). The rates of decay and hydrolysis, thus obtained, are given in Table I.
Bilirubin decay occurred at similar, rapid rates in guinea pig and rat bile, but proceeded very slowly in canine and human bile. Hydrolysis of conjugated bilirubin also was rapid in guinea pig

TABLE I

Decay of bilirubin and hydrolysis of conjugate in bile in vitro*

\begin{tabular}{|c|c|c|c|c|c|c|}
\hline \multirow[b]{3}{*}{ Source of bile } & \multicolumn{3}{|c|}{ Rate of decrease } & \multirow{2}{*}{\multicolumn{2}{|c|}{$\begin{array}{c}\text { Initial bilirubin } \\
\text { concentration, }\end{array}$}} & \multirow{3}{*}{$\begin{array}{l}\text { Unconjugated } \\
\text { bilirubin, } \\
\text { per cent } \\
\text { of total }\end{array}$} \\
\hline & \multirow{2}{*}{$\begin{array}{l}\text { Direct- } \\
\text { reacting } \\
\text { bilirubin }\end{array}$} & \multirow{2}{*}{$\begin{array}{c}\text { Total } \\
\text { bilirubin } \\
(=\text { decay })\end{array}$} & \multirow{2}{*}{$\begin{array}{c}\text { Direct - } \\
\text { total } \\
\text { (= hydrolysis) }\end{array}$} & & & \\
\hline & & & & Direct & Total & \\
\hline & \multicolumn{3}{|c|}{ per cent/hr } & \multicolumn{2}{|c|}{$\mathrm{mg} / 100 \mathrm{ml}$} & \\
\hline \multirow{7}{*}{$\begin{array}{l}\text { Guinea pig, } \\
\text { common duct }\end{array}$} & 56 & 23 & 33 & 1.11 & 1.18 & 5.3 \\
\hline & 25 & 16 & 9 & 2.93 & 2.38 & 10.8 \\
\hline & 15 & 9 & 6 & 3.02 & 3.30 & 8.6 \\
\hline & 39 & 34 & 5 & 1.49 & 1.54 & 3.3 \\
\hline & 20 & 16 & 4 & 1.65 & 1.70 & 2.9 \\
\hline & 36 & 33 & 3 & 1.72 & 1.79 & 3.9 \\
\hline & 30 & 29 & 1 & 1.13 & 1.15 & 2.2 \\
\hline \multirow{6}{*}{$\begin{array}{l}\text { Rat, } \\
\text { common duct }\end{array}$} & 25 & 20 & 5 & 21.8 & 22.8 & 4.5 \\
\hline & 18 & 15 & 3 & 19.4 & 19.6 & 0.9 \\
\hline & 25 & 22 & 3 & 8.2 & 9.0 & 8.9 \\
\hline & 24 & 21 & 3 & 20.9 & 21.3 & 2.2 \\
\hline & 24 & 23 & 1 & 12.5 & 12.7 & 1.7 \\
\hline & 18 & 17 & 1 & 12.7 & 13.2 & 3.8 \\
\hline \multirow{2}{*}{$\begin{array}{l}\text { Dog, } \\
\text { gall bladder }\end{array}$} & 6 & 5 & 1 & 118.6 & 119.0 & 0.3 \\
\hline & 3 & 3 & $\mathbf{0}$ & 187.0 & 187.5 & 0.2 \\
\hline \multirow{4}{*}{$\begin{array}{l}\text { Human, } \\
\text { T-tube }\end{array}$} & 8 & 4 & 4 & 30.4 & 31.9 & 7.7 \\
\hline & 6 & 2 & 4 & 22.6 & 23.4 & 3.7 \\
\hline & 9 & 5 & 4 & 80.0 & 81.5 & 1.9 \\
\hline & 13 & 11 & 2 & 60.7 & 64.4 & 5.7 \\
\hline
\end{tabular}

* $5.0 \mathrm{ml}$ of bile was incubated for $2.5 \mathrm{hr}$ in the dark at $37^{\circ} \mathrm{C}$ under an air atmosphere. Each set of values was derived from the decay curves obtained with a single bile sample from one animal. Samples are listed in order of decreasing rates of hydrolysis. 
bile, and quite variable from sample to sample, in contrast to the bile from the other three species, wherein hydrolysis rates were minimal and uniform. Rates of hydrolysis were unrelated to either the initial pigment concentration or to the total per cent of unconjugated bilirubin in the individual bile samples.

Absorption of bilirubin ${ }^{14} C$ from rat bile. These findings suggested that variable rates of hydrolysis might account for the variable rates of absorption observed with conjugated bilirubin $-{ }^{14} \mathrm{C}$ in guinea pig bile. Therefore, guinea pigs were studied after instillation into the gall bladder of $0.06-0.07 \mu \mathrm{mole} /$ $\mathrm{ml}$ of labeled bilirubin dissolved in rat bile (Fig. $6)$. In this vehicle, concentrations of other organic constituents are similar to guinea pig bile, but hydrolysis of conjugated bilirubin is minimal.

Compared to the studies with guinea pig bile, unconjungated bilirubin $-{ }^{14} \mathrm{C}$ was absorbed with equal rapidity. However, after administration of conjugated bilirubin- ${ }^{14} \mathrm{C}$, rates of absorption of label were consistently lower and more reproduc- ible in rat bile; they remained relatively constant over the $6 \mathrm{hr}$ period, and did not show the progressive decline observed with guinea pig bile. Recoveries of radioactivity in the various tissues and fluids were comparable to those obtained with guinea pig bile as the vehicle.

Effect of concentration on bilirubin absorption from bile. These preliminary studies indicated that maximal absorption with minimal decay and hydrolysis of pigment occurred during the 1st $\mathrm{hr}$ after instillation of labeled bilirubin into the gall bladder. Therefore, in subsequent experiments, bile excreted during the 1 st $\mathrm{hr}$ was collected in four consecutive, 15-min fractions, and the maximal initial rate of bilirubin absorption was determined from the largest quantity of isotope excreted in any of these four collection periods. In most experiments, only a small quantity of label was excreted during the first $15 \mathrm{~min}$, and the maximal rate was attained during the second $15 \mathrm{~min}$ period.

Over a range of concentrations from 0.04 to 0.20

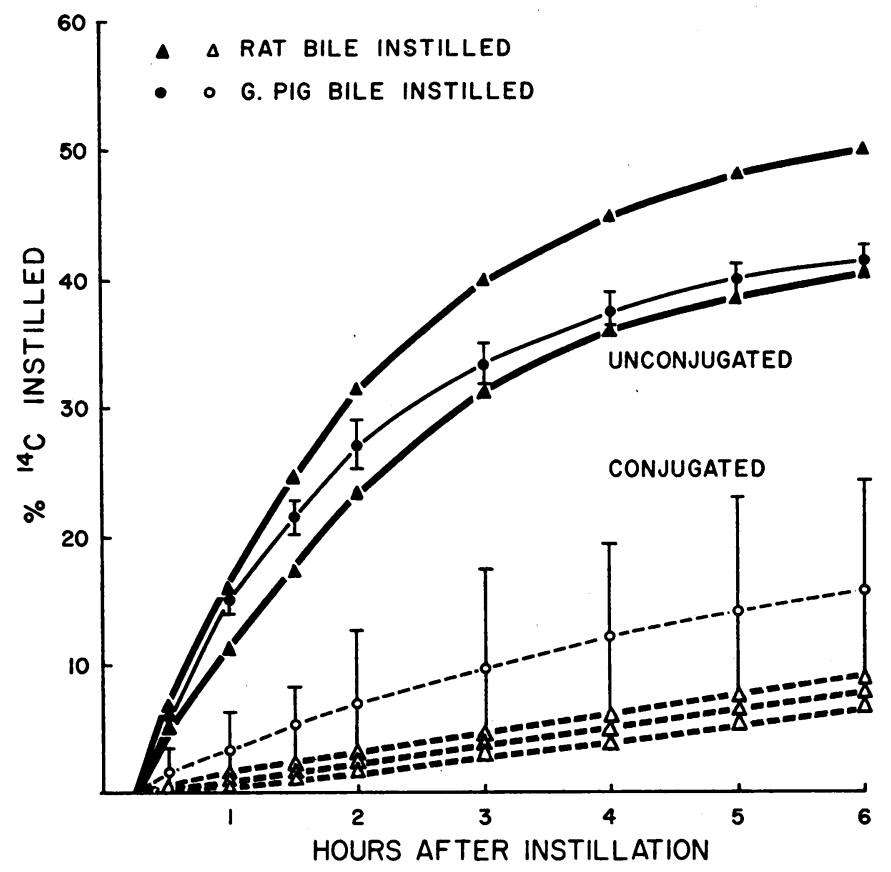

Fig. 6. Cumulative excretion of Radioactivity in hepatic BILE AFTER INSTILlation INTO GALL BLADDER OF BILIRUBIN $-{ }^{14} \mathrm{C}$ DISSOLVED IN RAT BILE. Heavy lines with triangles represent data obtained from individual guinea pigs after administration of 0.06$0.07 \mu$ mole of labeled conjugated or unconjugated bilirubin. Light lines with circles are the curves from experiments with guinea pig bile, replotted from Fig. 3 for comparison. 


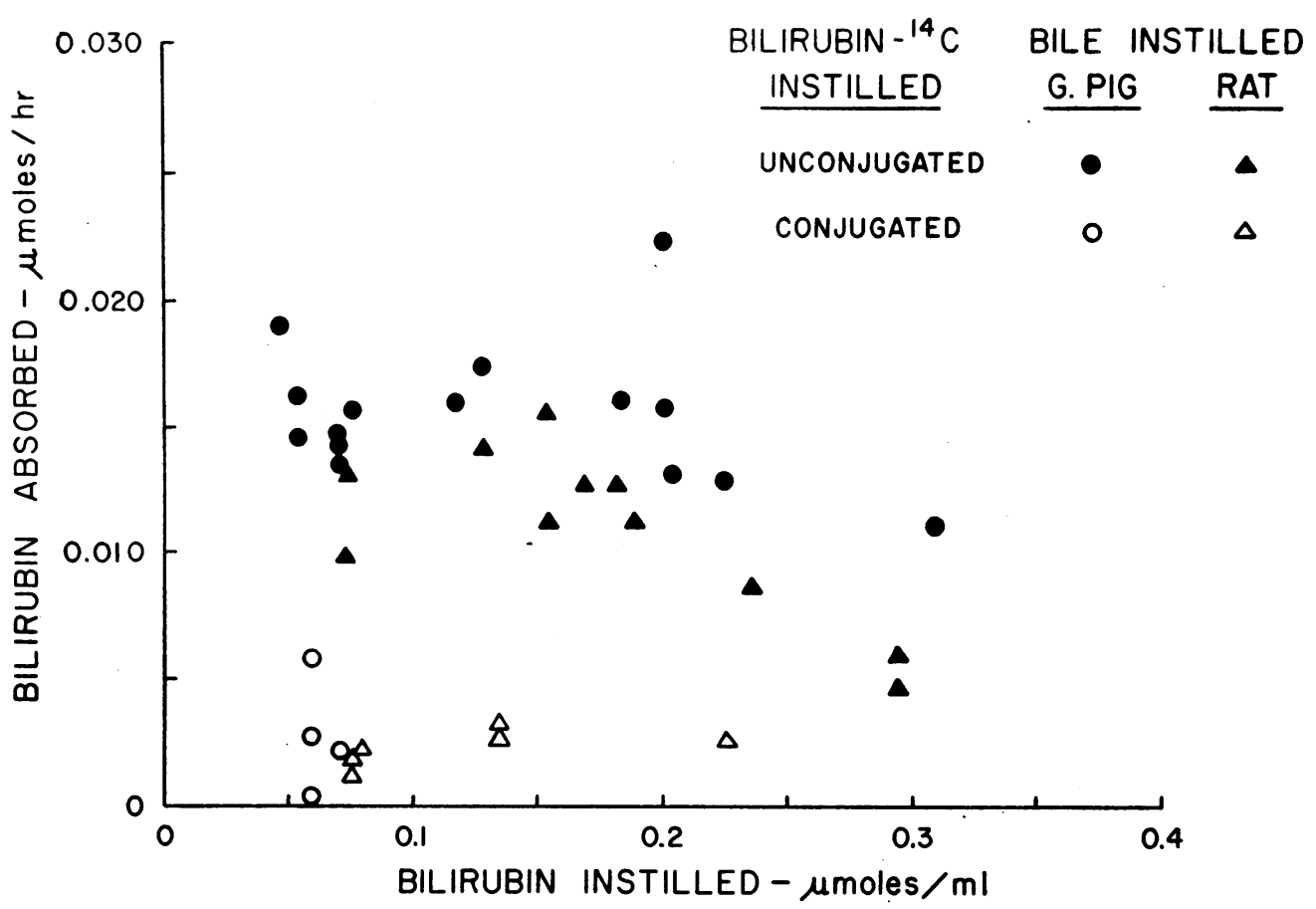

Fig. 7. EfFect of CONCENTRATION ON ABSORPTION OF BILIRUBIN- ${ }^{14} C$ FROM BILE. Bilirubin absorption was determined from the maximal initial rate of excretion of absorbed label in hepatic bile (see text). Unconjugated or conjugated bilirubin $-{ }^{14} \mathrm{C}$ was instilled into gall bladder in $1.0 \mathrm{ml}$ of guinea pig bile or rat bile. Each point represents the rate observed with a single guinea pig.

$\mu \mathrm{mole} / \mathrm{ml}$, absorption of unconjugated bilirubin${ }^{14} \mathrm{C}$ occurred at maximal rates that averaged 0.016 $\mu \mathrm{mole} / \mathrm{hr}$ from guinea pig bile and $0.012 \mu \mathrm{mole} / \mathrm{hr}$ from rat bile (Fig. 7 ). The highest rates attained by any single animal were 0.022 and $0.016 \mu \mathrm{mole} /$ $\mathrm{hr}$, respectively. At concentrations above 0.20 $\mu \mathrm{mole} / \mathrm{ml}$, the rates of absorption may have declined, but, due to the scatter of the data, the exact relationship between pigment absorption and concentration is uncertain.

After administration of conjugated bilirubin $-{ }^{14} \mathrm{C}$ over the same range of concentrations (Fig. 7), label was absorbed at rates approximately one-sixth of those observed with the unconjugated pigment (mean $=0.0025 \mu \mathrm{mole} / \mathrm{hr}$ ). Thus, under conditions in which the quantity of administered bilirubin was not rate-limiting, the gall bladder preferentially absorbed unconjugated bilirubin from bile $(P<0.01) .^{17}$

Absorption of unconjugated bilirubin ${ }^{14} C$ from bile salt solutions. When unconjugated bilirubin${ }^{14} \mathrm{C}$ was dissolved in solutions of taurochenode- oxycholate in saline, the pattern of absorption differed from that observed with bile (Fig. 8). Over the range of bilirubin concentrations up to approximately $0.1 \mu \mathrm{mole} / \mathrm{ml}$, maximal initial rates of pigment absorption were proportional to pigment concentration. At higher concentrations, bilirubin absorption did not increase further, and remained essentially constant at rates that averaged 0.020 $\mu \mathrm{mole} / \mathrm{hr}$. Rates of bilirubin absorption were similar in $0.5,2.0$, and $5.0 \mathrm{~mm}$ taurochenodeoxycholate, even though $0.5 \mathrm{~mm}$ is well below and $5.0 \mathrm{~mm}$ is well above the critical micellar concentration for this bile salt in solutions of similar nature (23-25).

Decay and absorption of urobilinogen. During incubation of five samples of guinea pig bile at $37^{\circ} \mathrm{C}$, their urobilinogen content declined exponentially at rates ranging from 9.7 to $32.3 \%$ / hr $(9.7,12.8,21.8,30.2$, and $32.3 \% / \mathrm{hr})$. At $0^{\circ} \mathrm{C}$, the urobilinogen content declined at rates of less than $2 \% / \mathrm{hr}$.

Administration of mesobilirubinogen- ${ }^{3} \mathrm{H}$, dis- 


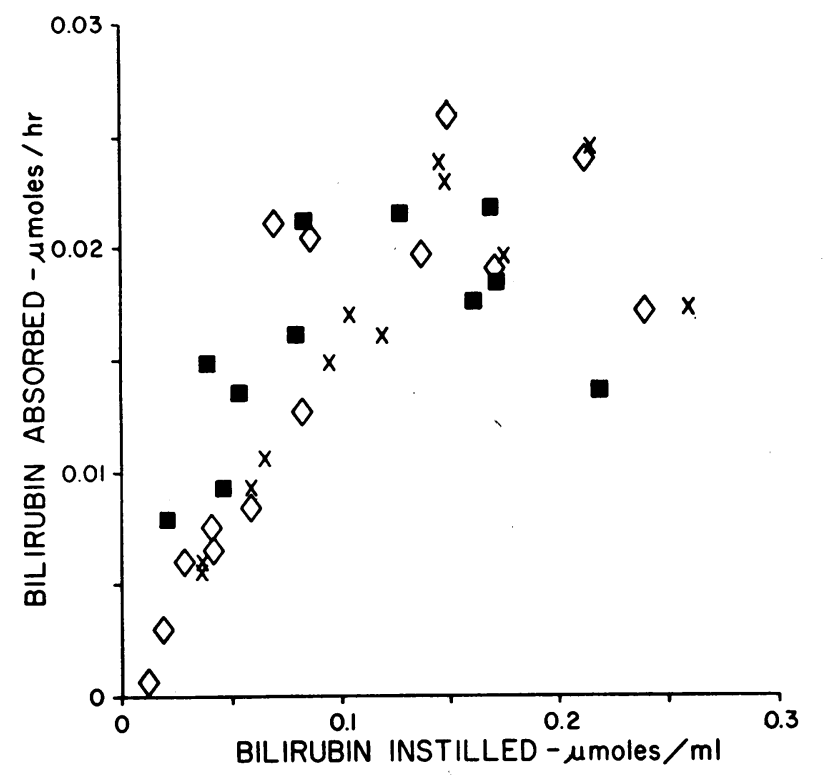

Fig. 8. EFFECt OF CONCENTRATION ON ABSORPtion OF UNCONJUGATED BILIRUBIN $-{ }^{14} \mathrm{C}$ FROM BILE SALT SOLUTIONS. Experiments performed and data plotted as in Fig. 7, except that unconjugated bilirubin- ${ }^{14} \mathrm{C}$ was instilled into gall bladder in $1.0 \mathrm{ml}$ of $0.5 \mathrm{~mm}(\diamond), 2.0$ $\mathrm{mM}(\boldsymbol{\square})$, or $5.0 \mathrm{~mm}(X)$ sodium taurochenodeoxycholate solution.

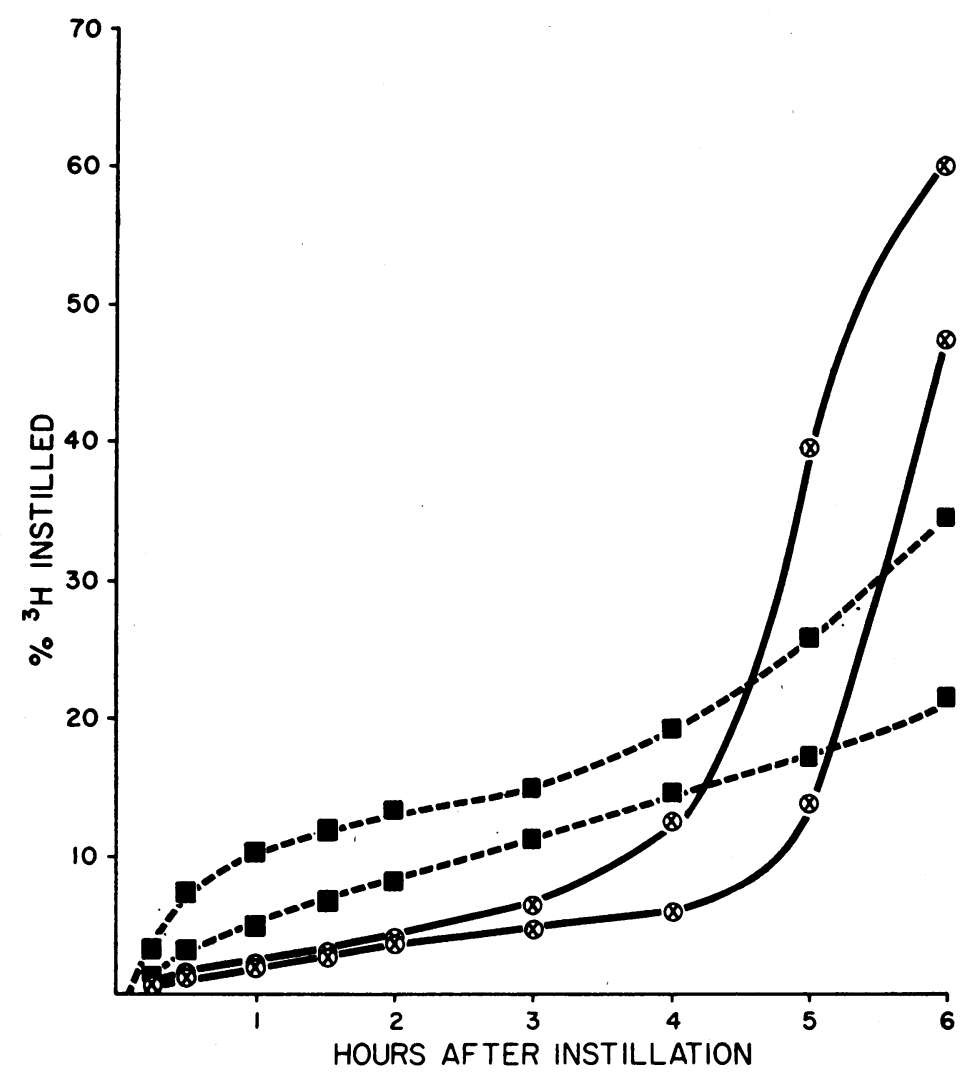

Fig. 9. Cumulative excretion of Radioactivity in hepatic bile AFTER INSTILLATION INTO GALL BLADDER OF MESOBILIRUBINOGEN ${ }^{-8} \mathrm{H}$ (UROBILINOGEN). Data plotted as in Fig. 6, with each curve representing a single animal. Labeled urobilinogen was administered in guinea pig bile $(\otimes-\otimes)$ or in $3.5 \mathrm{~mm}$ sodium taurocholate solution ( $\mathbf{\square - -} \square)$. 


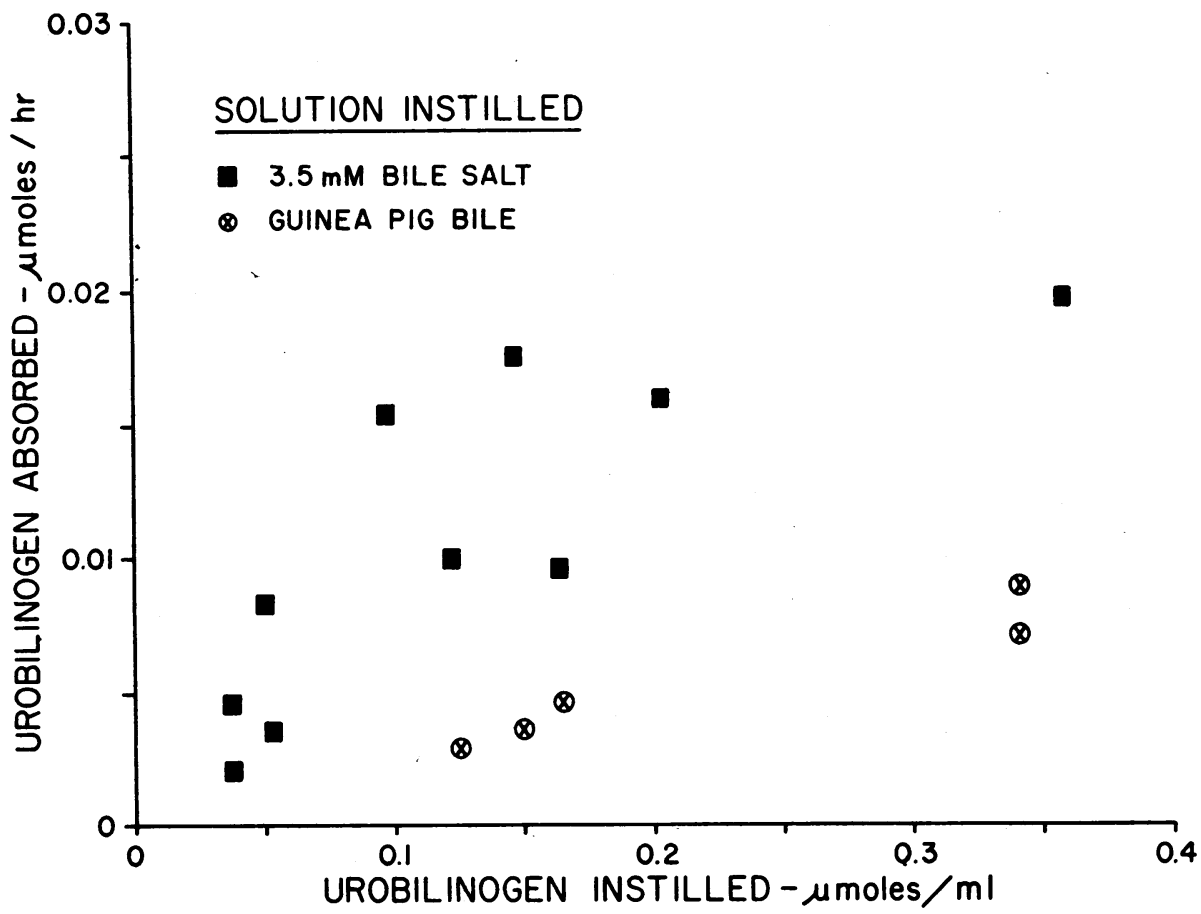

Fig. 10. EFfect of concentration on absorption of Mesobilirubinogen- ${ }^{8} \mathrm{H}$ (UROBiliNOGEN). Experiments performed and data plotted as in Fig. 7. Labeled urobilinogen was instilled into the gall bladder in $1.0 \mathrm{ml}$ of guinea pig bile or $3.5 \mathrm{~mm}$ sodium taurocholate solution.

solved in guinea pig bile, resulted in a peculiar pattern of isotope excretion (Fig. 9). After moderately rapid excretion during the 1 st $\mathrm{hr}$, a slow steady rate was maintained through the 3 rd or 4 th $\mathrm{hr}$, whereafter the rate rose precipitously. This late rise in excretion was sometimes seen also after administration of urobilinogen in bile salt solution, though only to a minor degree (Fig. 9) ; it never occurred with bilirubin. In all cases, the $\mathrm{pH}$ of the gall bladder contents remained constant at 8.2. As with bilirubin, maximal absorption of mesobilirubinogen $-{ }^{3} \mathrm{H}$ was determined from the phase of rapid biliary excretion of label that occurred during the 1 st $\mathrm{hr}$ after administration of labeled pigment. Total recoveries of isotope were comparable to those obtained with bilirubin $-{ }^{14} \mathrm{C}$, but only $51 \%$ of the tritium excreted in the bile was identified as mesobilirubinogen $-{ }^{3} \mathrm{H}$.

In $3.5 \mathrm{~mm}$ taurocholate-saline solution (Fig. 10)', absorption of urobilinogen rose proportionally as pigment concentration was increased up to 0.10 $\mu \mathrm{mole} / \mathrm{ml}$, but absorption showed little further increase at higher concentrations. At all concentra- tions, the rates of absorption were similar to those observed with bilirubin in bile salt solutions. When administered in guinea pig bile, however, (Fig. 10), urobilinogen absorption proceeded at rates only one-fourth to one-half those obtained with unconjugated bilirubin. Addition of equimolar quantities of unlabeled, unconjugated bilirubin actually enhanced the absorption of meso-

TABLE II

Effect of unconjugated bilirubin on absorption of mesobilirubinogen- ${ }^{3} H^{*}$

\begin{tabular}{|c|c|c|}
\hline \multirow{2}{*}{$\begin{array}{l}\text { Mesobili- } \\
\text { rubinogen-- } \\
\text { instilled }\end{array}$} & \multicolumn{2}{|c|}{$\begin{array}{l}\text { Maximal initial absorption } \\
\text { of mesobilirubinogen }\end{array}$} \\
\hline & $\begin{array}{l}\text { No bili- } \\
\text { rubin added }\end{array}$ & $\begin{array}{c}\text { Bilirubin } \\
\text { added }\end{array}$ \\
\hline umoles & 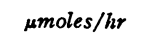 & umoles $/ \mathrm{hr}$ \\
\hline $\begin{array}{l}0.038 \\
0.051 \\
0.073\end{array}$ & $\begin{array}{l}0.0019 \\
0.0031 \\
0.0087\end{array}$ & $\begin{array}{l}0.0045 \\
0.0048 \\
0.0097\end{array}$ \\
\hline
\end{tabular}

* Labeled mesobilirubinogen with or without equimolar quantities of unlabeled unconjugated bilirubin was instilled into the gall bladder in $1.0 \mathrm{ml}$ of $3.5 \mathrm{~mm}$ taurocholate solution. 
TABLE III

Effects of albumin-binding on absorption of unconjugated bilirubin-14 $C^{*}$

\begin{tabular}{|c|c|c|c|c|}
\hline \multirow[b]{2}{*}{ Vehicle } & \multicolumn{2}{|c|}{$\begin{array}{c}\text { Solution instilled into } \\
\text { gall bladder }\end{array}$} & \multirow[b]{2}{*}{$\begin{array}{c}\text { No. } \\
\text { of } \\
\text { animals }\end{array}$} & \multirow[b]{2}{*}{$\begin{array}{l}\text { Maximal initial } \\
\text { absorption rates }\end{array}$} \\
\hline & $\begin{array}{l}\text { Bilirubin } \\
\text { instilled }\end{array}$ & $\begin{array}{c}\text { Molar } \\
\text { ratio of } \\
\text { albumin to } \\
\text { bilirubin }\end{array}$ & & \\
\hline & umoles & & & umoles/hr \\
\hline Guinea pig bile & 0.053 & 2.70 & 2 & $0.002-0.003$ \\
\hline Saline & 0.056 & 2.55 & 3 & $0.002-0.004$ \\
\hline Guinea pig bile & $0.050-0.062$ & 0 & 5 & $0.013-0.016$ \\
\hline
\end{tabular}

* Crystalline bovine albumin added to yield final concentration of $10 \mathrm{mg} / \mathrm{ml}$.

bilirubinogen $-{ }^{3} \mathrm{H}$ from $3.5 \mathrm{~mm}$ taurocholate solution (Table II).

Effect of albumin-binding on bilirubin absorption. Dialysis experiments demonstrated that each mole of bovine albumin could bind tightly 1 mole of bilirubin; yet, when 2.5 moles of albumin per mole of bilirubin was added to the solutions instilled into the gall bladder, unconjugated bilirubin${ }^{14} \mathrm{C}$ was still absorbed, although at rates approximately one-fifth of those observed without added albumin (Table III). The rates were the same whether the pigment and protein were dissolved in guinea pig bile or in saline solution. Water absorption was unaltered.

Effect of metabolic inhibitors on bilirubin absorption (Table IV). Addition of 0.05 or of 0.5 mM iodacetamide to the instilled solution did not impair absorption of either water or unconjugated bilirubin ${ }^{14} \mathrm{C}$. A concentration of $1.5 \mathrm{~mm}$ iodoacetamide abolished net water movement but did not alter either the maximal rate of bilirubin absorption or the total quantity absorbed in $6 \mathrm{hr}$. An increase of the iodoacetamide concentration to $5.0 \mathrm{~mm}$ resulted in lysis of the mucosa, which mixed with the instilled bile to form a gelatinous mass. Even under these circumstances, bilirubin absorption was not abolished, although it was reduced by approximately two-thirds.

$0.5 \mathrm{~mm}$ Dinitrophenol did not affect either water or bilirubin absorption. At dinitrophenol concentrations of 1.0 and $2.5 \mathrm{~mm}$, however, the mucosa was damaged histologically and more fluid escaped from the lumen, yet bilirubin absorption remained unaffected or was slightly increased. Higher concentrations of dinitrophenol could not be tested due to problems with solubility.

Studies with photo-oxidized bilirubin-14 $C$. After intravenous injection, water-soluble, photo-oxidative derivatives of bilirubin- ${ }^{14} \mathrm{C}$ were excreted principally in the urine rather than in the bile (Table

TABLE IV

Effects of metabolic inhibitors on absorption of unconjugated bilirubin- ${ }^{14} \mathrm{C}$

\begin{tabular}{|c|c|c|c|c|c|c|c|}
\hline \multicolumn{3}{|c|}{ Solution instilled into gall bladder* } & \multirow{3}{*}{$\begin{array}{l}\text { No. } \\
\text { of } \\
\text { animals }\end{array}$} & \multirow{2}{*}{\multicolumn{2}{|c|}{$\begin{array}{l}\text { Gall bladder residual } \\
\text { after } 6 \mathrm{hr}\end{array}$}} & \multicolumn{2}{|c|}{ Bilirubin absorption } \\
\hline \multicolumn{2}{|c|}{ Inhibitor } & \multirow{2}{*}{$\begin{array}{l}\text { Unconjugated } \\
\text { bilirubin-4C }\end{array}$} & & & & & Total \\
\hline Compound & Concentration & & & Volume & Consistency & Maximal rate & absorbed \\
\hline Iodoacetamide & $\begin{array}{l}m M \\
0.05 \\
0.5 \\
1.5 \\
5.0\end{array}$ & $\begin{array}{l}\mu \text { moles } \\
0.064 \\
0.066 \\
0.070 \\
0.057\end{array}$ & $\begin{array}{l}1 \\
3 \\
3 \\
2\end{array}$ & $\begin{array}{c}m l \\
0.4 \\
0.4-0.5 \\
0.9-1.0 \\
1.2-1.4\end{array}$ & $\begin{array}{l}\text { Fluid } \\
\text { Fluid } \\
\text { Viscid } \\
\text { Gel }\end{array}$ & $\begin{array}{c}\mu m o l e s / h r \\
0.016 \\
0.017-0.018 \\
0.014-0.018 \\
0.004 \& 0.006\end{array}$ & $\begin{array}{c}\mu \text { moles } / 6 \mathrm{hr} \\
0.032 \\
0.031-0.035 \\
0.028-0.032 \\
0.011 \& 0.018\end{array}$ \\
\hline Dinitrophenol & $\begin{array}{l}0.5 \\
1.0 \\
2.5\end{array}$ & $\begin{array}{l}0.072 \\
0.051 \\
0.076\end{array}$ & $\begin{array}{l}1 \\
3 \\
3\end{array}$ & $\begin{array}{c}0.4 \\
0.15-0.25 \\
0.10-0.20\end{array}$ & $\begin{array}{l}\text { Fluid } \\
\text { Fluid } \\
\text { Fluid }\end{array}$ & $\begin{array}{c}0.014 \\
0.013-0.016 \\
0.013-0.016\end{array}$ & $\begin{array}{c}0.028 \\
0.029-0.034 \\
0.029-0.034\end{array}$ \\
\hline None & (Control) & $0.050-0.073$ & 6 & $0.3-0.5$ & Fluid & $0.013-0.016$ & $0.026-0.032$ \\
\hline
\end{tabular}

* Solutions were prepared with guinea pig bile as described under Methods. $1.0 \mathrm{ml}$ of solution was initially instilled into the gall bladder. 
V). A mean of only $71 \%$ administered radioactivity was recovered over the $6 \mathrm{hr}$ collection period. After instillation of these derivatives into the gall bladder (Table VI), maximal excretion rates in bile never exceeded $0.0012 \mu \mathrm{mole} / \mathrm{hr}$. During the $6 \mathrm{hr}$ collection period, total recovery of radioactivity averaged only $88 \%$, with $1.9-7.6 \%$ in the urine, $5.3-7.7 \%$ in the liver, $62.0-92.0 \%$ in the gall bladder residual, and only $0.8-4.0 \%$ in the hepatic bile. Obviously, biliary excretion of label could not be used as an accurate measure of the absorption of photo-oxidative derivatives from the gall bladder.

Histology of the gall bladder. $20 \mathrm{hr}$ after instillation of solutions prepared with whole bile, or with $2 \mathrm{~mm}$ conjugated bile salt in saline, the gall bladder remained normal, histologically, except for some edema and acute inflammatory infiltrate in the serosa. However, after 4 or more hr exposure to 3.5 or $5.0 \mathrm{~mm}$ solutions of conjugated bile salts, the mucosa exhibited massive edema of the lamina propria and patchy flattening or denudation of the epithelial cells. Instillation of $0.15 \mathrm{~mm}$ deoxycholate, equivalent to the concentrations of unconjugated bile salt contaminants in the solutions of conjugated bile salts, produced no histologic abnormalities.

\section{Discussion}

The present investigation has demonstrated significant absorption of unconjugated bilirubin by the in situ guinea pig gall bladder. These results contradict the prevailing view $(2,3)$ that the gall bladder does not absorb bile pigments. This view
TABLE V

Excretion by the guinea pig of photo-oxidative derivatives of bilirubin-14 $C^{*}$

\begin{tabular}{cccccc}
\hline \hline \multirow{2}{*}{$\begin{array}{c}\text { Duration of } \\
\text { illumination }\end{array}$} & \multicolumn{5}{c}{ Recoveries of radioactivity after $6 \mathrm{hr}$} \\
\cline { 2 - 6 } & Bile & Urine & Liver & Plasma & Total \\
\hline $\mathrm{hr}$ & $\%$ & $\%$ & $\%$ & $\%$ & $\%$ \\
1.0 & 25.2 & 45.1 & 1.1 & 0.7 & 72.1 \\
3.0 & 11.6 & 56.7 & 1.0 & 0.6 & 68.9 \\
5.0 & 4.6 & 65.7 & 1.3 & 0.4 & 72.0
\end{tabular}

* Bilirubin- ${ }^{14} \mathrm{C}$ dissolved in $0.1 \mathrm{~N}$ sodium hydroxide was illuminated under a mercury lamp for the duration indicated, then neutralized with buffered bovine albumin. Each solution, equivalent to $0.09 \mu$ mole bilirubin-14 $\mathrm{C}$, was administered intravenously to a guinea pig with an external bile fistula and ligated cystic duct.

was based upon experiments conducted with canine bile (4), wherein virtually all bilirubin is conjugated and little hydrolysis occurs. Thus, absorption of unconjugated pigment was never investigated, and the techniques used were not sufficiently accurate to detect the limited absorption of conjugated bilirubin that was demonstrated with the sensitive isotopic method utilized in the present study.

This method, in which absorption of labeled bilirubin was determined from the subsequent excretion of radioactivity in hepatic bile, was validated by the following observations. (a) Labeled bilirubin was excreted much more rapidly when administered intravenously than after instillation into the gall bladder. This indicated that absorption from the gall bladder, and not biliary excretion of label, was the rate-limiting step.

(b)

TABLE VI

Gall bladder absorplion of photo-oxidative derivatives of bilirubin-14 C

\begin{tabular}{|c|c|c|c|c|c|c|c|}
\hline \multicolumn{2}{|c|}{ Derivatives instilled } & \multicolumn{5}{|c|}{ Recoveries of radioactivity $6 \mathrm{hr}$ after administration } & \multirow[b]{2}{*}{$\begin{array}{c}\text { Maximal biliary } \\
\text { excretion }\end{array}$} \\
\hline $\begin{array}{l}\text { Duration } \\
\text { of illu- } \\
\text { mination }\end{array}$ & $\begin{array}{l}\text { Quantity } \\
\text { instilled* }\end{array}$ & $\begin{array}{l}\text { Gall } \\
\text { bladder } \\
\text { residual }\end{array}$ & $\underset{\text { bile }}{\text { Hepatic }}$ & Urine & Liver & Total & \\
\hline$h r$ & umoles & & & & & & $\mu$ moles $/ h r$ \\
\hline 1.0 & 0.095 & 79.5 & 4.0 & 7.6 & 5.5 & 90.9 & 0.0012 \\
\hline 1.0 & 0.087 & 84.7 & 3.6 & 4.8 & 5.7 & 84.0 & 0.0007 \\
\hline 3.0 & 0.070 & 92.0 & 0.8 & 1.9 & 7.7 & 104.0 & 0.0002 \\
\hline 3.0 & 0.070 & 77.5 & 1.8 & 2.7 & 5.3 & 89.3 & 0.0004 \\
\hline 5.0 & 0.069 & 66.3 & 1.4 & 6.2 & 5.9 & 81.7 & 0.0003 \\
\hline 5.0 & 0.069 & 62.0 & 1.5 & 9.2 & 5.4 & 79.7 & 0.0002 \\
\hline
\end{tabular}

${ }^{*}$ Expressed as $\mu$ mole of bilirubin-14 $\mathrm{C}$ that were photo-oxidized to form the labeled derivatives that were administered. Derivatives were dissolved in guinea pig bile for instillation into the gall bladder.

$\ddagger$ Includes $0.6-1.2 \%$ in the gall bladder wall and $0.4-1.1 \%$ in the plasma. 
Total recovery of radioactivity exceeded $95 \%$ of the quantity instilled into the gall bladder. (c) After administration of labeled bilirubin, most of the radioactivity that disappeared from the gall bladder was recovered in hepatic bile as bilirubin${ }^{14} \mathrm{C}$. (d) Photo-oxidative derivatives of bilirubin- ${ }^{14} \mathrm{C}(10)$, which resemble the polar, water-soluble decay products of bilirubin in bile (22), were poorly absorbed and appeared principally in the urine rather than the bile. However, absorption was slightly underestimated by this method because (a) about $1 \%$ of the administered radioactivity appeared in the urine, and $(b)$ during transit, about $5 \%$ of the administered radioactivity was stored in the gall bladder wall, liver, and plasma. It must be remembered also that the rate of absorption of a radioactive tracer ard the corresponding unlabeled compound may differ (26). These arguments apply also to the studies of urobilinogen absorption.

Mechanisms of bile pigment absorption. Over a range of concentrations that were not rate-limiting, lipid-soluble unconjugated bilirubin and urobilinogen were absorbed rapidly, whereas watersoluble conjugated bilirubin was absorbed poorly, if at all. Since the rates of absorption of conjugate paralleled the rates of its hydrolysis in guinea pig as compared to rat bile, most of the apparent absorption of labeled conjugate probably resulted from prior hydrolysis to the unconjugated form that was then absorbed. However, it seems likely that some conjugated bilirubin was absorbed intact because photo-oxidative derivatives of bilirubin and other water-soluble organic anions of similar molecular size ${ }^{1}$ were also absorbed to a limited extent. These observations agree with studies of bile pigment absorption from the intestine (17, 19, 27).

The relationship between lipid solubility and absorption, just noted, suggested that the bile pigments were absorbed principally by diffusion in their unionized form, but indicated that the gall bladder was slightly permeable also to certain organic anions. A mechanism of passive diffusion was supported also by the finding that iodoacetamide and dinitrophenol did not inhibit bilirubin transfer at concentrations that altered net water movement. This indicated that bilirubin absorption was probably not an active, energy-dependent process, and showed also that it was unrelated to net water transport and therefore not mediated by solvent drag. Failure of bilirubin to inhibit the absorption of urobilinogen- ${ }^{3} \mathrm{H}$ (Table II) provided further evidence against a common, carriermediated, transport system for these bile pigments. Finally, the linear relationship between absorption and concentration of pigment, observed at low concentrations of bilirubin and urobilinogen in simple salt solutions (Figs. 8 and 10), was most compatible with passive diffusion as the mechanism of pigment transfer across the gall bladder.

Effects of interactions of bilirubin with other constituents of bile. Such a simple mechanism of absorption by passive diffusion cannot account for several phenomena that were observed. (a) Rates of absorption of bilirubin and urobilinogen reached a constant "plateau" at higher pigment concentrations. (b) Kinetics of absorption of bilirubin and urobilinogen differed in whole bile as compared to bile salt solutions. (c) Rates of absorption of bilirubin from bile salt solutions were apparently independent of the presence of micelles (Fig. 8). (d) Absorption of urobilinogen from whole bile increased strikingly $4 \mathrm{hr}$ after instillation (Fig. 9). As will be discussed, these phenomena seem best explained by interactions between the bile pigments and other constituents of bile, which presumably modified the kinetics of pigment absorption. Ideally, absorption should have been studied in the absence of interactions between the pigments and bile salts $(28,29)$ or cholesterol-lecithin-bile salt micelles $(30,31)$. Unfortunately, this was not possible, because unconjugated bilirubin is not soluble in simple aqueous-electrolyte solutions, and conjugated bilirubin is not available in a pure, stable form and must be administered in native bile.

In both bile and bile salt solutions, increases in pigment concentration above approximately 0.05 and $0.1 \mathrm{~mm}$, respectively, were not accompanied by further, proportionate increments in pigment absorption, as measured by biliary excretion of label. It has already been indicated that biliary excretion was not rate-limiting. Whether blood flow from the gall bladder to the liver was limiting in the healthy animals could not be determined, but seems unlikely, although absorption of pigment was severely impaired in animals who were in 
shock or in whom the cystic vessels were occluded. $^{19}$ It is possible also that the plateau in absorption rates resulted from interactions of pigment with the mucosal membrane. However, the maximum rates of bilirubin absorption differed in bile salt solution, guinea pig bile, and rat bile, which suggests that interactions with components of the lumenal fluid played the major role in the appearance of the plateau.

A surprising finding was that rates of bilirubin absorption were similar in solutions of taurochenodeoxycholate, both below $(0.5 \mathrm{~mm})$ and above $(5.0 \mathrm{~mm})$ the critical micellar concentrations for this bile salt. Theoretically, in mixed micelles, only the detergent molecules (bile salts) are in equilibrium with molecules in the surrounding aqueous medium (32). Therefore, pigment molecules bound in micelles should presumably not contribute to the diffusion gradient across the gall bladder, and micellar interaction would be expected to retard the absorption of bilirubin. Since bilirubin was solubilized, it is evident that it interacted with $0.5 \mathrm{~mm}$ taurochenodeoxycholate even without micelle formation, and it may be that this nonmicellar interaction retards diffusion of bilirubin as effectively as micellar binding of pigment. Alternatively, the mucosal membrane may possess limited ability to dissociate bilirubin from micelles, a process akin to the dissociation of bilirubin from its complex with albumin during diffusion of bilirubin across the placenta (33). In this regard, it is of interest that some bilirubin was absorbed by the gall bladder in the presence of sufficient albumin to bind the bilirubin so completely that no unbound fraction could be detected by dialysis (Table III).

The exact nature of the interactions between bilirubin and other constituents of bile, and the mechanisms by which they alter pigment absorption, are unclear. The present data merely indicate that such interactions exist and apparently affect the patterns of pigment absorption.

Effects of mucosal injury on bile pigment absorption. The observed absorption of bilirubin and urobilinogen from whole bile was not due to nonspecific leakage through a damaged mucosa, since: (a) mucosal histology remained normal; (b) transport of water occurred at rates similar

19 Ostrow, J. D. Unpublished observations. to those reported by others (34), and was similarly affected by metabolic inhibitors $(34,35) ;(c)$ absorption of unconjugated bilirubin and urobilinogen was selective; and $(d)$ absorption of bilirubin was retarded by binding to albumin. Thus, after instillation of whole bile, the gall bladder mucosa functioned normally. By contrast, the mucosa was damaged histologically by simple solutions of conjugated bile salts at concentrations equal to those present in whole guinea pig bile (36 and footnote $1)$. It was shown that this damage could not be attributed to the small amounts of contaminating unconjugated bile salts. Similar toxic effects on the gall bladder mucosa (5) and other membranes $(37,38)$ have been described previously for conjugated $(5,37)$ and unconjugated (38) bile salts, but only at concentrations 3-20 times those used in the present study. In whole bile, interactions of bile salts with other constituents apparently protect the gall bladder mucosa against such injury (5, 39 , and footnote 20).

This mucosal damage was not the cause of the different patterns of absorption observed when bilirubin or urobilinogen was administered in simple bile salt solutions, as compared to whole bile, because: (a) kinetics of bilirubin absorption were similar in $0.5,2.0$, and $5.0 \mathrm{~mm}$ taurochenodeoxycholate solutions, yet mucosal damage was detected only with the highest bile salt concentration; $(b)$ absorption rates were determined during the 1 st $\mathrm{hr}$ after administration of pigment, and several hours before mucosal injury could be detected; and $(c)$ rates of bilirubin absorption are similar in gall bladders previously injured by bile salts and in undamaged gall bladders. ${ }^{20}$ It thus seems that the kinetics of pigment absorption were unaffected by mucosal injury by bile salts.

The late rise in absorption of urobilinogen (Fig. 9) was also unrelated to mucosal damage. Thus, the late rise did not occur with bilirubin $-{ }^{14} \mathrm{C}$, was prominent in whole bile that did not damage the mucosa, and was minimal when the mucosa was injured by instillation of $3.5 \mathrm{~mm}$ taurocholate solutions. In addition, the late rise was not due to a decline in $\mathrm{pH}$ with a resultant increase in the unionized, diffusible fraction of urobilinogen, since no change in the $\mathrm{pH}$ of the lumenal fluid occurred

${ }^{20}$ Ostrow, J. D. Effects of injury by bile salts on gall bladder absorption of organic anions. In preparation. 
during the $6 \mathrm{hr}$ study period. It is suggested that the late rise was related to changing interactions of urobilinogen with other bile constituents as the proportion of urobiniogen was decreased by its selective reabsorption.

Mechanisms of the formation of "white bile." The present studies confirm the speculation of Riegel et al. (40) that absorption and decay of bile pigments contribute to the formation of "white bile" in the totally obstructed gall bladder (40-42) or biliary tree (43-46). It has been shown here that the loss of pigment results from: $(a)$ hydrolysis of conjugated bilirubin to the unconjugated form, which is then absorbed; and $(b)$ decay of bilirubin to colorless derivatives, which are in part absorbed. In these and other circumstances, these processes may limit accumulation of poorly soluble, unconjugated bilirubin, and thus prevent its precipitation in bile. More rapid rates of pigment decay and hydrolysis in guinea pig bile (Table I) may account for the observation that "white bile" is formed in the occluded guinea pig gall bladder within 5 days, ${ }^{19}$ as compared to a minimum of 2 or more wk in the dog $(41,42)$ and in the human (40). These data contravert the contention that mucosal damage $(40,44,46)$ or overt bacterial infection $(47,48)$ is essential for "white bile" formation. They also invalidate the use of relative bilirubin contents to assess the ability of the gall bladder to concentrate hepatic bile (45).

Mechanism of hepatic excretion of bile pigments. The data in Table I confirm earlier reports that unconjugated bilirubin is found consistently in mammalian bile, as detected by the indirect diazo reaction (present paper, 49-51), solvent partition methods $(52,53)$, or chromatographically as Pigment I (53-57), an equimolar complex of bilirubin and its diglucuronide $(13,58,59)$. The presence of unconjugated bilirubin is not, as others have claimed $(49,60,61)$, simply an artefact produced by hydrolysis of excreted conjugate, since: $(a)$ in this investigation, indirect bilirubin was detected in biles collected freshly on ice and in the dark, conditions that virtually abolished in vitro hydrolysis of bilirubin conjugates; and $(b)$ in an individual bile sample, the per cent of unconjugated bilirubin was unrelated to the rate of hydrolysis of conjugated bilirubin in vitro. Unconjugated bilirubin is found also in the bile of amphibia (62), rats $(60,63,64)$, and humans (65) who cannot synthesize bilirubin glucuronide. Therefore, in contradiction of the current belief $(60,66,67)$ that conjugation is essential for the secretion of bilirubin into the bile canaliculus, it seems likely that unconjugated bilirubin may be secreted also by the liver cell. The predominance of conjugated bilirubin in mammalian common duct bile $(49,54$, 68-70) might then be due to selective reabsorption of lipid-soluble, unconjugated pigment by the biliary tree, akin to that demonstrated in the present studies with the gall bladder. This hypothesis may seem untenable in view of the failure of Stumpf and Lester (71) to detect tritium-label in the biliary epithelium in microadioautographs of rat liver obtained soon after intravenous injection of mesobilirubinogen- ${ }^{3} \mathrm{H}$. However, in view of the limited gall bladder absorption of urobilinogen from whole bile (Fig. 10), their negative finding may reflect an insufficiently sensitive method, rather than the absence of pigment absorption. For the present, it can only be speculated that unconjugated bilirubin may be secreted by the hepatocyte and then preferentially reabsorbed in the biliary tree. Definitive evaluation of this hypothesis awaits the development of techniques to directly measure the composition of primary canalicular bile and the rates of transfer of bile solutes across the biliary epithelium (72).

\section{Acknowledgments}

The author gratefully acknowledges the technical assistance of Mr. Norman Ingrassia and Mr. Ajitkumar Munshi, and the advice and support of Dr. Leslie T. Webster, Jr., and Dr. Tomuo Hoshiko. $\mathrm{He}$ also wishes to thank Drs. Robert E. Eckel, Bernard R. Landau, Oscar D. Ratnoff, and Harold P. Roth for their critical review of the manuscript.

\section{References}

1. Ostrow, J. D. 1965. Absorption of organic substances by the gallbladder. Clin. Res. 13: 258. (Abstr.)

2. Ivy, A. C. 1934. Physiology of the gall bladder. Physiol. Rev. 14 : 1.

3. Diamond, J. M. 1965. The concentrating ability of the gall bladder. In The Biliary System. W. Taylor, editor. Blackwell Scientific Publications, Oxford. 495.

4. Riegel, C., C. G. Johnston, and I. S. Ravdin. 1932. Studies on gall bladder function. VIII. The fate of bile pigment and cholesterol in hepatic bile subjected to gall bladder activity. J. Exptl. Med. 56: 1. 
5. Riegel, C., I. S. Ravdin, and C. G. Johnston. 1932. Studies of gall bladder function. VI. The absorption of bile salts and cholesterol from the bile-free gall bladder. Am. J. Physiol. 99: 656.

6. Ostrow, J. D., L. Hammaker, and R. Schmid. 1961. The preparation of crystalline bilirubin- $\mathrm{C}^{14}$. $J$. Clin. Invest. 40: 1442.

7. Lester, R., and P. D. Klein. 1966. Bile pigment excretion: a comparison of the biliary excretion of bilirubin and bilirubin derivatives. J. Clin. Invest. 45 : 1839.

8. Kottke, B. A., J. Wollenweber, and C. A. Owen, Jr. 1966. Quantitative thin-layer chromatography of free and conjugated cholic acid in human bile and duodenal contents. J. Chromatog. 21: 439.

9. Umbreit, W. W., R. H. Burris, and J. F. Stauffer. 1949. Manometric Techniques and Tissue Metabolism. Burgess Publishing Co., Minneapolis. 2nd edition. 119.

10. Ostrow, J. D. 1967. Photo-oxidative derivatives of ${ }^{14} \mathrm{C}$-bilirubin and their excretion by the Gunn rat. In Bilirubin Metabolism. I. A. D. Bouchier and B. H. Billing, editors. Blackwell Scientific Publications, Oxford. 117.

11. Herman, R. H., T. H. Wilson, and L. Kazyak. 1958. Electrolyte migrations across the wall of the guinea pig gall bladder. J. Cellular Comp. Physiol. 51 : 133.

12. Malloy, H. T., and K. A. Evelyn. 1937. The determination of bilirubin with the photoelectric colorimeter. J. Biol. Chem. 119 : 481.

13. Nosslin, B. 1960. Direct diazo reaction of bile pigments in serum: experimental and clinical studies. Scand. J. Clin. Lab. Invest. Suppl. $49: 1$.

14. Gregory, C. H., and C. J. Watson. 1962. Studies of conjugated bilirubin. I. Comparison of conventional fractional determination with chromatographic and solvent partition methods for free and conjugated bilirubin. J. Lab. Clin. Med. $60: 1$.

15. Michaëlsson, M. 1961. Bilirubin determination in serum and urine. Studies on diazo methods and a new copper-azo pigment method. Scand. J. Clin. Lab. Invest. Suppl. 5 : 1.

16. Watson, C. J., and V. Hawkinson. 1947. Studies of urobilinogen. VI. Further experience with the simple quantitative Ehrlich reaction. Corrected calibration of the Evelyn colorimeter with a pontacyl dye mixture in terms of urobilinogen. $\mathrm{Am}$. J. Clin. Pathol. 17 : 108.

17. Lester, R., and R. Schmid. 1963. Intestinal absorption of bile pigments. I. The enterohepatic circulation of bilirubin in the rat. J. Clin. Invest. 42 : 736.

18. Ostrow, J. D., J. H. Jandl, and R. Schmid. 1962. The formation of bilirubin from hemoglobin in vivo. J. Clin. Invest. 41 : 1628.

19. Lester, R., and R. Schmid. 1965. Intestinal absorption of bile pigments. III. The enterohepatic circulation of urobilinogen in the rat. J. Clin. Invest. 44: 722 .
20. Ostrow, J. D., and R. Schmid. 1963. The proteinbinding of ${ }^{14} \mathrm{C}$-bilirubin in murine and human serum. J. Clin. Invest. 42: 1286.

21. Edwards, A. L. 1954. Statistical Methods for the Behavioral Sciences. Holt, Rinehart \& Winston Inc., New York. 1st edition.

22. Ostrow, J. D. 1967. Mechanism for the appearance of unconjugated bilirubin in bile. Gastroenterology. 52: 321. (Abstr.)

23. Miyake, H., T. Murakoshi, and T. Hisatsugu. 1962. Studies on taurine conjugated bile acids. (in Japanese, English Summary). Fukuoka Acta Med. $53: 695$.

24. Hofmann, A. F. 1963. The function of bile salts in fat absorption. The solvent properties of dilute micellar solutions of conjugated bile salts. Biochem. J. 89 : 57.

25. Tamesue, N., and K. Juniper, Jr. 1967. Concentrations of bile salts at the critical micellar concentration of human gall bladder bile. Gastroenterology. 52 : 473.

26. Nims, L. F. 1962. Tracers, transfer through membranes, and coefficients of transfer. Science. 137: 130.

27. Lester, R., and R. Schmid. 1963. Intestinal absorption of bile pigments. II. Bilirubin absorption in man. New Engl. J. Med. 269 : 178.

28. Sakamoto, T. 1956. Studies on bile pigments. IV. Direct bilirubin in canine bile. Acta Med. Okayama. 10: 227.

29. Yamamoto, S. 1958. Studies on the relation between bilirubin and bile salts. II. The molecular compound of bilirubin and bile acid. Igaku Kenkyu. $28: 29$.

30. Juniper, K., Jr. 1965 . Physiochemical characteristics of bile and their relation to gallstone formation. Am. J. Med. 39 : 98.

31. Nakayama, F., and H. Miyake. 1966. Species differences in cholesterol-complexing macromolecular fractions in bile in relation to gallstone formation. J. Lab. Clin. Med. $67: 78$.

32. Small, D. M. 1967. Physiochemical studies of cholesterol gallstone formation. Gastroenterology. 52 : 607.

33. Schenker, S., N. H. Dawber, and R. Schmid. 1964 Bilirubin metabolism in the fetus. J. Clin. Invest. $43: 32$.

34. Diamond, J. M. 1964. Transport of salt and water in rabbit and guinea pig gall bladder. J. Gen. Physiol. 48: 1 .

35. Kang, D. H., and S. K. Hong. 1962. Water and chloride exchange across the gall bladder of the anesthetized dog. Am. J. Physiol. 203 : 1015.

36. Chenderovitch, J., E. Phocas, and M. Rautureau. 1963. Effects of hypertonic solutions on bile formation. Am. J. Physiol. $205: 863$.

37. Pethica, B. A., and J. H. Schulman. 1952. Hemolytic and surface activity of sodium taurocholate. Nature. (London). 170: 117. 
38. Dawson, A. M., and K. J. Isselbacher. 1960. Studies on lipid metabolism in the small intestine with observations on the role of bile salts. J. Clin. Invest. $39: 730$.

39. Wilkie, A. L., and H. Doubilet. 1933. Passage of cholesterol through the mucosa of the gall bladder. Arch. Surg. 26: 110.

40. Riegel, C., I. S. Ravdin, C. G. Johnston, and P. J. Morrison. 1935. Studies of gall bladder function. XII. The composition of "white bile." $\mathrm{Am}$. J. Med. Sci. 190: 655 .

41. McMaster, P. D., G. O. Broun, and P. Rous. 1923. Studies on the total bile. III. On the bile changes caused by a pressure obstacle to secretion; and on hydrohepatosis. J. Exptl. Med. $37: 685$.

42. Elman, R., and E. A. Graham. 1932. The pathogenesis of the "strawberry" gallbladder (cholesterolosis of the gallbladder). Arch. Surg. $24: 14$.

43. Rous, P., and P. D. McMaster. 1921. Physiological causes for the varied character of stasis bile. $J$. Exptl. Med. 34 : 75.

44. Stewart, H. L., and M. M. Lieber. 1935. Ligation of the common bile duct in the cat. Arch. Pathol. 19: 34.

45. Schmidt, C. R., and A. C. Ivy. 1937. The general function of the gall bladder: Do species lacking a gall bladder possess its functional equivalent? The bile and pigment output of various species of animals. J. Cell. Comp. Physiol. 10: 365 .

46. Haber, M. H., and K. R. Rees. 1963. The production and composition of white bile in the rat. $J$. Pathol. Bacteriol. 85 : 127.

47. Aronsohn, H. G. 1934. Pathogenesis of "white bile." Proc. Soc. Exptl. Biol. Med. 32: 695.

48. Bernhard, F. 1933. Experimentelle und klinische Untersuchungen über das Zustandekommen des Hydrops der Gallenwege oder der sog. weissen Galle. Arch. Klin. Chir. 178: 495.

49. Billing, B. H., P. G. Cole, and G. H. Lathe. 1957. The excretion of bilirubin as a diglucuronide giving the direct van den Bergh reaction. Biochem. J. $65: 774$.

50. Gastaldi, F., and F. Testoni. 1947. Contributo allo studio della bilirubino indiretta; caratteri differenziali fra bilirubina indiretta e bilirubina diretta acida. Boll. Soc. Ital. Biol. Sper. $23: 689$.

51. Bonomo, E., and B. Colombo. 1959. L'eliminazione per via biliare della bilirubina e dell'acido glucuronico nel ratto in corso di carico con bilirubina indiretta. Arch. Ital. Mal. Appar. Dig. 26: 162.

52. Berthelot, P. 1967. Excretion of unconjugated bilirubin in rat bile. In Bilirubin Metabolism. I. A. D. Bouchier and B. H. Billing, editors. Blackwell Scientific Publications, Oxford. 189.

53. Schalm, L., and A. Ph. Weber. 1962. Bilirubin pigments in blood and bile after loading with bilirubin in man. Ned. Tijdschr. Geneesk. 106: 1079.

54. Hoffman, H. N., II, F. F. Whitcomb, Jr., H. R. Butt, and J. L. Bollman. 1960. Bile pigments of jaundice. J. Clin. Invest. 39 : 132.
55. Billing, B. H., and G. H. Lathe. 1958. Bilirubin metabolism in jaundice. Am. J. Med. $24: 111$.

56. Kuenzle, C. C., C. Maier, and J. R. Rüttner. 1966. The nature of four bilirubin fractions from serum and of three bilirubin fractions from bile. J. Lab. Clin. Med. 67: 294.

57. Noir, B. A., E. R. Garay, and M. Royer. 1965. Separation and properties of conjugated biliverdin. Biochim. Biophys. Acta. (Amsterdam). 100: 403.

58. Weber, A. Ph., L. Schalm, and J. Witmans. 1963. Bilirubin monoglucuronide (Pigment I) : a complex. Acta Med. Scand. 173: 19.

59. Gregory, C. H. 1963. Studies of conjugated bilirubin. III. Pigment I, a complex of conjugated and free bilirubin. J. Lab. Clin. Med. 61: 917.

60. Schmid, R., J. Axelrod, L. Hammaker, and R. L. Swarm. 1958. Congenital jaundice in rats, due to a defect in glucuronide formation. J. Clin. Invest. $37: 1123$.

61. Gray, C. H. 1961. Bile Pigments in Health and Disease. Charles C Thomas, Springfield. 47.

62. Lester, R., and R. Schmid. 1961. Bile pigment excretion in amphibia. Nature. (London.). 190: 452.

63. Schmid, R., and L. Hammaker. 1963. Metabolism and disposition of $\mathrm{C}^{\mathbf{1 4}}$-bilirubin in congential nonhemolytic jaundice. J. Clin. Invest. 42: 1720.

64. Arias, I. M., L. Johnson, and S. Wolfson. 1961. Biliary excretion of injected conjugated and unconjugated bilirubin by normal and Gunn rats. Am. J. Physiol. 200: 1091.

65. Billing, B. H., C. H. Gray, A. Kulczycka, P. Manfield, and D. C. Nicholson. 1964. The metabolism of ${ }^{14} \mathrm{C}$-bilirubin in congenital non-hemolytic hyperbilirubinemia. Clin. Sci. 27: 163.

66. Lester, R., and R. Schmid. 1964. Bilirubin metabolism. New Engl. J. Med. 270: 779.

67. Schmid, R. 1966. Hyperbilirubinemia. In The Metabolic Basis of Inherited Disease. J. B. Stanbury, J. B. Wyngaarden, and D. S. Fredrickson, editors. Blakiston, New York. 2nd edition. 877.

68. Schmid, R. 1957. The identification of "direct-reacting" bilirubin as bilirubin glucuronide. $J$. Biol. Chem. 229 : 881.

69. Isselbacher, K. J., and E. A. McCarthy. 1959. Studies on bilirubin sulfate and other nonglucuronide conjugates of bilirubin. J. Clin. Invest. $38: 645$.

70. Noir, B. A., A. T. DeWalz, and E. Rodriguez Garay. 1967. Studies on bilirubin sulphate in human bile. In Bilirubin Metabolism. I. A. D. Bouchier and B. H. Billing, editors. Blackwell Scientific Publications, Oxford. 99.

71. Stumpf, W. E., and R. Lester. 1966. Secretion and absorption of mesobilirubinogen- $\mathrm{H}^{3}$ studied by autoradiography. Lab. Invest. $15: 1156$.

72. Brauer, R. W. 1965. Hepatic blood supply and the secretion of bile. In The Biliary System. W. Taylor, editor. Blackwell Scientific Publications, Oxford. 54. 